\title{
IONP-doped nanoparticles for highly effective NIR-controlled drug release and combination tumor therapy
}

This article was published in the following Dove Press journal:

International Journal of Nanomedicine

16 May 2017

Number of times this article has been viewed

\section{Xudong $\mathrm{Fu}^{\prime}$ \\ Xinjun Wang' \\ Shaolong Zhou' \\ Yanyan Zhang ${ }^{2}$}

'The Fifth Affiliated Hospital of Zhengzhou University, ${ }^{2}$ School of Basic Medical Sciences, Zhengzhou University, Zhengzhou, People's Republic of China
Correspondence: Yanyan Zhang School of Basic Medical Sciences, Zhengzhou University, 100 Kexue Avenue, Zhengzhou 45000I, People's Republic of China Email fxd1064@I26.com

\begin{abstract}
Despite advances in controlled drug delivery, drug delivery systems (DDSs) with controlled activated drug release and high spatial and temporal resolution are still required. Theranostic nanomedicine is capable of diagnosis, therapy, and monitoring the delivery and distribution of drug molecules and has received growing interest. In this study, a near-infrared light-controlled "off-on" DDS with magnetic resonance imaging and magnetic targeting properties was developed using a hybrid nanoplatform (carbon nanotubes [CNTs]-iron oxide nanoparticle). Doxorubicin (DOX) and distearoyl-sn-glycero-3-phosphoethanolamine-PEG were adsorbed onto CNTs-iron oxide nanoparticle, and then to avoid the unexpected drug release during circulation, 1-myristyl alcohol was used to encapsulate the CNTs-drug complex. Herein, multifunctional DOX-loaded nanoparticles (NPs) with "off-on" state were developed. DOX-NPs showed an obvious "off-on" effect (temperature increase, drug release) controlled by near-infrared light in vitro and in vivo. In the in vivo and in vitro studies, DOX-NPs exhibited excellent magnetic resonance imaging ability, magnetic targeting property, high biosafety, and high antitumor combined therapeutic efficacy (hyperthermia combined with chemotherapy). These results highlight the great potential of DOX-NPs in the treatment of cancer.
\end{abstract}

Keywords: controlled drug release, magnetic targeting, MRI, combination therapy

\section{Introduction}

Cancer is a major cause of mortality worldwide, and its incidence continues to increase, with $>10$ million new cases reported every year. ${ }^{1}$ Currently, the conventional treatments for cancers are limited to chemotherapy, radiotherapy, and surgery. Unfortunately, chemotherapy and radiotherapy often have negative effects on normal cells, resulting in serious side effects, such as neuropathy, neutropenia, and kidney failure. $^{2-4}$ Since the past decade, with the rapid development of nanotechnology, nanoparticles with little toxicity and high biocompatibility have been widely used as carriers for efficient drug delivery.,

However, most particulate-based drug delivery systems (DDSs) always suffer from unexpected drug release during circulation, which leads to unexpected side effects. ${ }^{7}$ Furthermore, the drug release in many DDSs relies on spontaneous degradation of the nanocarriers in vivo and does not allow for controlled drug release. Many of the reported DDSs could not release the drug immediately when the DDS arrived at the tumor site. After the DDS returns to the blood circulation, a considerable part of drug is still present in the DDS, and this always affects the efficacy of treatment. ${ }^{8}$ To address the above problems, an ideal DDS should be able to encapsulate the drugs efficiently before reaching the tumor ("off" state); once it arrives at the tumor cells or tissues, 
the loaded drugs should be released immediately ("on" state). One alternative that has been developed in the past few years is the concept of stimuli-responsive DDSs, which allow for tailored release profiles with spatial, temporal, and dosage control. ${ }^{9,10}$ These stimuli-responsive systems consist of triggering the release of the therapeutic drug at the diseased site through the use of diverse entities that are sensitive to exogenous stimuli (ie, temperature, light, magnetic fields, electric fields, and ultrasound) or endogenous stimuli (ie, changes in $\mathrm{pH}$, redox potential, or the concentrations of enzymes or specific analyses). ${ }^{11-14}$

Among the feasible external stimuli, light represents a unique and exciting method for achieving spatiotemporal control of the drug release at the tumor site. ${ }^{15}$ However, the preparation of most of the light-regulated DDSs is complicated. Furthermore, the traditional utilization of ultraviolet radiation and the poor tissue penetration capability of visible light limit their applications. ${ }^{16}$ In fact, near-infrared (NIR) light (700-900 nm) can penetrate deep into the body with focused beams, which allows local therapy avoiding the adverse side effects to healthy tissues. ${ }^{17}$ Recently, NIR light-response DDSs based on SPR of the noble metal nanoparticles (AuNPs and AgNPs) have received increasing attention for their novel capacity of controlling drug release. ${ }^{18}$ However, some problems of AuNP- or AgNP-based DDSs still remain unresolved. These include the low drug loading capacity because of the small specific surface area and the weak adsorption capacity of AuNPs to small molecular drugs. Carbon nanotubes (CNTs) with low systemic toxicity, large specific surface area, and strong photothermal conversion capacity in NIR range have shown tremendous promise in NIR light triggered delivery of drugs in the body. ${ }^{19}$ More importantly, compared with AuNPs or AgNPs, a large range of therapeutic drugs (ie, nucleic acid, peptide, small molecule drugs) can be loaded on CNTs with high loading efficacy by simple adsorption. ${ }^{20-22}$

In order to avoid the unexpected drug release during circulation, 1-myristyl alcohol (1-MA) with a phase transition temperature of $\sim 42^{\circ} \mathrm{C}$ was used to encapsulate the CNTsdrug complex. ${ }^{23}$ When the ambient temperature was below $42^{\circ} \mathrm{C}$ (during circulation), drug-loaded CNTs were encapsulated in the 1-MA in solid phase and the drugs could not be released ("off"). Once NIR light was passed, CNTs adsorbed the energy of NIR light and generated a large amount of heat, leading to the melting of 1-MA; the encapsulated drugs and CNTs could then be released quickly (“on") (Figure 1).

Tumor-targeted delivery is a key requirement for tumor therapy. Recently, magnetic targeting, an attractive physical targeting technique, is garnering substantial attention for drug delivery applications. ${ }^{24-26}$ Iron oxide nanoparticle (IONP) is

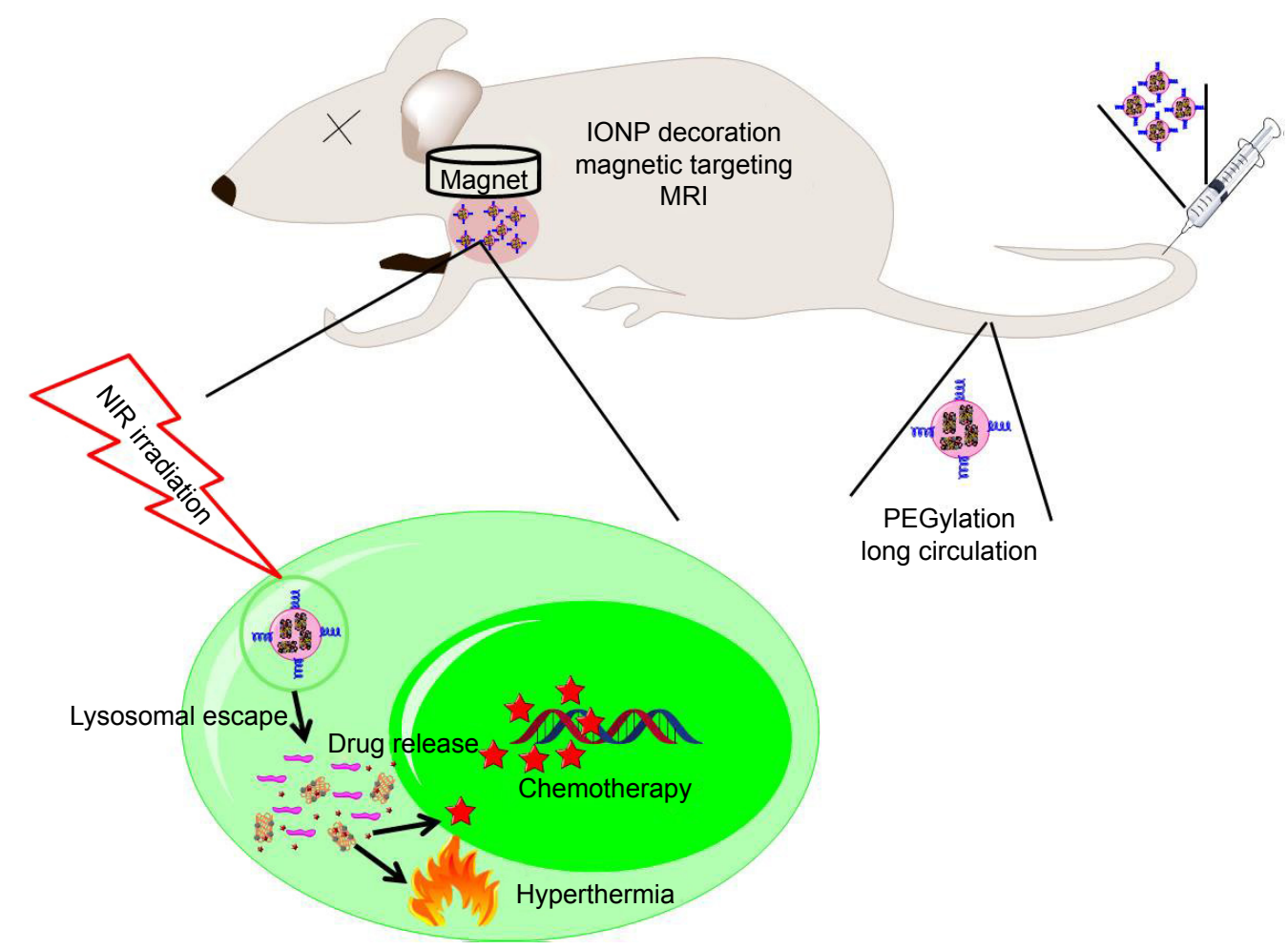

Figure I DOX-NP and its biofunctions.

Abbreviations: DOX, doxorubicin; MRI, magnetic resonance imaging; NIR, near infrared; NP, nanoparticle; IONP, iron oxide nanoparticle. 
one of the Food and Drug Administration-approved materials used in vivo and has been utilized in the magnetic separation of biological entities, hyperthermia treatment, magnetic resonance imaging (MRI), and drug delivery. ${ }^{27-30}$ Upon intravenous administration, IONPs concentrate at the tumor site using an external high-gradient magnetic field. ${ }^{31}$ In this study, IONPs were linked to CNTs to obtain magnetic targeting and MRI effects in the tumor-bearing mice models (Figure 1).

In this study, we developed a novel magnetic targeting theranostic DDS with “off-on" state controlled by NIR light to maximize the antitumor efficacy and minimize the systemic toxicity to normal tissues. Figure 1 shows the synthesis of CNTs-IONP nanocomposite, loading an antitumor drug doxorubicin (DOX), and functionalization by distearoyl-snglycero-3-phosphoethanolamine-PEG (DSPE-PEG2000). Finally, 1-MA was used to encapsulate the CNTs-drug complex. Herein, a multifunctional nanoparticle was developed and characterized by transmission electron microscopy (TEM), dynamic laser scattering (DLS), nanotracing analysis (NTA), and vibrating sample magnetometer. The "off-on" state, magnetic targeting, MRI, and antitumor effects of the multifunctional nanoparticles were examined using 4T1 cells and 4T1 tumor-bearing mice models.

\section{Experimental section Materials}

Single-walled CNTs (purity 0.90\%) were purchased from Shenzhen Nanotech Port (Shenzhen, People's Republic of China). DOX (production date: 2014/05/11, purity >98\%) was obtained from Beijing Yi-He Biotech Co. Ltd. 1-MA, distearoyl-sn-glycero-3-phosphoethanolamine-PEG (DSPEPEG), and dimethyl sulfoxide were obtained from SigmaAldrich Co. LLC. Sulforhodamine B, Dulbecco's Modified Eagle's Medium (DMEM) cell culture medium, penicillin, streptomycin, fetal bovine serum (FBS), and heparin sodium were bought from Gibco Invitrogen. DAPI and hematoxylin and eosin (H\&E) were supplied by Beyotime Biotechnology Co. Ltd. Other reagents were acquired from China National Medicine Corporation Ltd. Also, 808 nm laser (diode laser, $2 \mathrm{~W} / \mathrm{cm}^{2}, \mathrm{CW}$ ) was supplied by Changchun Laser Research Center. The dialysis bags ( $\mathrm{MWCO}=10,000$ ) were obtained from Spectrum Laboratories Inc.

\section{Synthesis of DOX-loaded nanoparticles (DOX-NPs)}

\section{Synthesis of CNTs-IONP}

The CNTs were oxidized by using acid mixture (nitric acid:hydrochloric acid $=3: 1$ ) as reported earlier. ${ }^{32}$ Then, CNTs-COOH (100 mg), $\mathrm{FeCl}_{3}(270 \mathrm{mg}$ ), and $\mathrm{NaOAc}$
(800 mg) were dissolved in a mixture of ethylene glycol $(0.5 \mathrm{~mL})$ and diethylene glycol $(9.5 \mathrm{~mL})$. The resulting solution was then transferred to a Teflon-lined stainless steel autoclave, which was sealed and heated at $200^{\circ} \mathrm{C}$ for $10 \mathrm{~h}$. The as-prepared CNTs-IONP was washed several times with ethanol and water and dried.

\section{Synthesis of DOX-loaded CNTs-IONP-PEG NPs}

CNTs-IONP (100 mg) were added to $100 \mathrm{~mL}$ of phosphatebuffered saline (PBS) solution containing DOX (150 mg) and DSPE-PEG $(10 \mathrm{mg})$ and then stirred at room temperature for $24 \mathrm{~h}$. After $24 \mathrm{~h}$, the resulting product was purified by high-speed centrifugation $(10,000 \times g)$ for $20 \mathrm{~min}$ to remove the free DOX and DSPE-PEG and then dried in vacuum and stored at $4^{\circ} \mathrm{C}$ until use. The amount of DOX loaded onto CNTs-IONP-PEG NPs was measured at $490 \mathrm{~nm}$ by ultraviolet-visible spectrometer.

\section{I-MA encapsulation}

In brief, 1-MA (500 mg) and DOX-loaded CNTs-IONP-PEG NPs $(100 \mathrm{mg})$ were mixed and heated at $\sim 50^{\circ} \mathrm{C}$. After 1-MA melted, the mixture was stirred at $50^{\circ} \mathrm{C}$ for $10 \mathrm{~min}$. Then, $50 \mathrm{~mL}$ of water $\left(50^{\circ} \mathrm{C}\right)$ was added drop wise to the mixture with vigorous stirring and then sonicated with an ultrasonic cell disruption system (400 W, 10 times) to obtain DOXNPs. The blank NPs (without DOX) were also prepared in the same way.

\section{Characterization}

DLS (Zetasizer Nano ZS-90; Malvern Instruments, Malvern, UK), TEM (Tecnai G2 20; FEI, Memphis, TN, USA), and NTA (Nanoslight 300, Malvern Instruments) were used for characterizing the zeta potential, particle size, and morphology of DOX-NPs and blank NPs, respectively. A vibrating sample magnetometer was used for characterizing the magnetic property of DOX-NPs. The $\mathrm{T}_{2}$-weighted MR images were obtained in vitro and in vivo on a $3 \mathrm{~T}$ clinical MRI scanner (SIEMENS).

\section{Evaluation of "off-on" state of DOX-NPs Photothermal effect of DOX-NPs with "off" or "on" state}

An NIR laser ( $\left.808 \mathrm{~nm}, 2 \mathrm{~W} / \mathrm{cm}^{2}\right)$ was used for photothermal therapy. DOX-NPs suspensions in water $(0.2 \mathrm{~mL})$ at different concentrations $(5,10$, and $15 \mu \mathrm{g} / \mathrm{mL})$ were irradiated by an $808 \mathrm{~nm}$ laser, continuous-wave NIR with a power density of $2 \mathrm{~W} / \mathrm{cm}^{2}$. The temperature was measured with a thermometer (HT-8878, ZhengZhou JinYangGuang Instrument Co. Ltd.). 
DOX release from DOX-NPs with "off" or "on"

state

DOX-NPs (DOX concentration: $0.5 \mathrm{mg} / \mathrm{mL}, 1 \mathrm{~mL}$ ) were sealed in dialysis membranes (MW cutoff $12-14 \mathrm{kDa}$, Spectrapor). The dialysis bags were incubated in $10 \mathrm{~mL}$ PBS buffer ( $\mathrm{pH} 7.4)$. They were irradiated with an $808 \mathrm{~nm}$ laser $\left(2 \mathrm{~W} / \mathrm{cm}^{2}, 6 \mathrm{~min}\right)$ at 6 and $14 \mathrm{~h}$. The DOX released in PBS was quantified by high-performance liquid chromatography under the following chromatographic conditions: an Eclipse XDB-C18 column $(150 \times 4.6 \mathrm{~mm}, 5.0 \mu \mathrm{m})$; mobile phase sodium acetate solution $(0.02 \mathrm{~mol} / \mathrm{L})$ : acetonitrile 80:20; column temperature $40^{\circ} \mathrm{C}$; fluorescence detector with the excitation and emission wavelengths set at 475 and $560 \mathrm{~nm}$, respectively; flow rate $1.0 \mathrm{~mL} / \mathrm{min}$; and injection volume $20 \mu \mathrm{L}$.

\section{In vitro studies using 4TI cells Cell culture}

4T1 cells (mice breast cancer cell line) were cultured in normal DMEM culture medium with $10 \%$ FBS and 1\% penicillin/streptomycin in $5 \% \mathrm{CO}_{2}$ and $95 \%$ air at $37^{\circ} \mathrm{C}$ in a humidified incubator.

\section{Cellular uptake}

Intracellular uptake of DOX-NPs was studied with 4T1 cells. $4 \mathrm{~T} 1$ cells were seeded at $5 \times 10^{4}$ cells per well on glass cover slips in 6-well plates. When the cells reached $70 \%$ confluence, they were treated with DOX-NPs (DOX concentration: $10 \mu \mathrm{g} / \mathrm{mL}$ and the fullerene concentration was around $30 \mu \mathrm{g} / \mathrm{mL}$ ) for $4 \mathrm{~h}$ with a magnet (magnetic field intensity: $0.3 \mathrm{~T}$ ) placed under the center of the culture dish. After staining with DAPI $(10 \mu \mathrm{g} / \mathrm{mL})$ for $15 \mathrm{~min}$, the cells were washed three times with PBS and imaged by a fluorescence microscope.

\section{"Off-on" DOX release of DOX-NPs in 4TI cells}

$4 \mathrm{~T} 1$ cells were seeded at $5 \times 10^{4}$ cells per well on glass cover slips in 6-well plates. When the cells reached $70 \%$ confluence, they were treated with DOX-NPs (DOX concentration: $10 \mu \mathrm{g} / \mathrm{mL}$ and the NP concentration was around $30 \mu \mathrm{g} / \mathrm{mL}$ ) for $4 \mathrm{~h}$ with a magnet (magnetic field intensity: $0.3 \mathrm{~T}$ ) placed under the center of the culture dish. Before NIR irradiation ("off" state), the cells were stained by DAPI $(10 \mu \mathrm{g} / \mathrm{mL})$ for $15 \mathrm{~min}$ and washed twice with PBS and then imaged. After NIR irradiation ("on" state, $808 \mathrm{~nm}$ laser radiation, $2 \mathrm{~W} / \mathrm{cm}^{2}, 6 \mathrm{~min}$ ), the cells were imaged by a fluorescence microscope (Zeiss LSM 510; Zeiss, Oberkochen, Germany).

\section{Cell viability measurements}

4T1 cells were plated in 96-well plates and then incubated for $24 \mathrm{~h}$. After incubation, the medium was replaced with fresh DMEM culture medium containing free DOX, blank NPs, and DOX-NPs (with the same DOX concentration $[10 \mu \mathrm{g} / \mathrm{mL}]$ and the same NP concentration [around $30 \mu \mathrm{g} / \mathrm{mL}$ ]) for $4 \mathrm{~h}$ with or without a magnet (magnetic field intensity: $0.3 \mathrm{~T}$ ). Then, the medium was replaced with fresh medium. After incubation for $4 \mathrm{~h}$, the cells were or were not irradiated with $808 \mathrm{~nm}$ lasers $\left(2 \mathrm{~W} / \mathrm{cm}^{2}, 6 \mathrm{~min}\right)$. Cytotoxicity studies using mouse hepatocyte cells (AML 12) were performed. In brief, AML 12 cells were plated in 96-well plates and then incubated for 3 days in a cell culture medium which was normal DMEM culture medium with 10\% FBS and $1 \%$ penicillin/streptomycin. After incubation, the medium was replaced with fresh medium containing blank NPs (30 $\mu \mathrm{g} / \mathrm{mL}$ ), DOX-NPs (DOX concentration: $10 \mu \mathrm{g} / \mathrm{mL}$, NPs concentration: around $30 \mu \mathrm{g} / \mathrm{mL})$, and DOX $(10 \mu \mathrm{g} / \mathrm{mL})$ for 3 days. Standard sulforhodamine B assay was carried out to determine cell viabilities.

\section{In vivo experiments \\ Xenograft tumor mouse model}

All animal experiments were performed with a protocol approved by Henan Laboratory Animal Center. The 4T1 tumor models were generated by subcutaneous injection of $2 \times 10^{6} 4 \mathrm{~T} 1$ cells in $0.1 \mathrm{~mL}$ saline into the right shoulder of female BALB/c mice (18-20 g, Henan laboratory animal center). The mice were used when the tumor volume reached 60-100 $\mathrm{mm}^{3}$ ( $\sim 6$ days after tumor inoculation).

\section{In vivo MRI}

For in vivo MRI, the 4T1 tumor-bearing mice were intravenously injected with DOX-NPs $(0.2 \mathrm{~mL}, 15 \mathrm{mg} / \mathrm{kg})$. After injection for $8 \mathrm{~h}$ with or without a magnet (magnetic field intensity $0.3 \mathrm{~T}$ ) glued on the tumor site, MRI was conducted on a $3 \mathrm{~T}$ clinical MRI scanner.

\section{Biodistribution}

Tumor-bearing mice (6 mice per group) were intravenously injected with $0.2 \mathrm{~mL}$ of DOX $(5 \mathrm{mg} / \mathrm{kg})$ and DOX-NPs (DOX: $5 \mathrm{mg} / \mathrm{kg}$, NPs: $15 \mathrm{mg} / \mathrm{kg}$ ). After injection for $8 \mathrm{~h}$ with or without a magnet (magnetic field intensity $0.3 \mathrm{~T}$ ) glued on the tumor site, the mice were sacrificed to collect heart, liver, spleen, lung, kidney, and tumor, weighed, and homogenized in buffer (methanol to saline ratio, 1:1). DOX in tissues was determined by high-performance liquid chromatography (1100 Agilent, USA) under the following 
chromatographic conditions: an Eclipse XDB-C18 column $(150 \times 4.6 \mathrm{~mm}, 5.0 \mu \mathrm{m})$; mobile phase sodium acetate solution $(0.02 \mathrm{~mol} / \mathrm{L})$ :acetonitrile $80: 20$; column temperature $40^{\circ} \mathrm{C}$; fluorescence detector with the excitation and emission wavelengths set at 475 and $525 \mathrm{~nm}$, respectively; flow rate $1.0 \mathrm{~mL} / \mathrm{min}$; and injection volume $20 \mu \mathrm{L}$.

\section{In vivo antitumor effect}

4T1 tumor-bearing mice were divided into 9 groups ( 5 mice per group), minimizing the differences in weights and tumor sizes in each group. The mice were administered the following: 1) saline $(0.2 \mathrm{~mL}) ; 2)$ saline + NIR $(0.2 \mathrm{~mL}$, $2 \mathrm{~W} / \mathrm{cm}^{2}, 6 \mathrm{~min}, 8 \mathrm{~h}$ postinjection); 3) DOX (5 mg/kg, $0.2 \mathrm{~mL})$; 4) blank NPs (15 mg/kg, $0.2 \mathrm{~mL}) ; 5)$ blank NPs + magnet (M) $(15 \mathrm{mg} / \mathrm{kg}, 0.2 \mathrm{~mL}$, a $0.3 \mathrm{~T}$ magnet glued onto the tumor); 6) blank NPs + M + NIR (15 mg/kg, $0.2 \mathrm{~mL}$, a $0.3 \mathrm{~T}$ magnet glued onto the tumor, $2 \mathrm{~W} / \mathrm{cm}^{2}, 6 \mathrm{~min}, 8 \mathrm{~h}$ postinjection); 7) DOX-NPs (DOX: $5 \mathrm{mg} / \mathrm{kg}$, NPs: $15 \mathrm{mg} / \mathrm{kg}$, $0.2 \mathrm{~mL}$ ); 8) DOX-NPs + M (DOX: $5 \mathrm{mg} / \mathrm{kg}$, NPs: $15 \mathrm{mg} / \mathrm{kg}$, $0.2 \mathrm{~mL}$, a 0.3 T magnet glued onto the tumor); and 9) DOXNPs + M + NIR (DOX: $5 \mathrm{mg} / \mathrm{kg}$, NPs: $15 \mathrm{mg} / \mathrm{kg}, 0.2 \mathrm{~mL}$, a $0.3 \mathrm{~T}$ magnet glued onto the tumor, $2 \mathrm{~W} / \mathrm{cm}^{2}, 6 \mathrm{~min}, 8 \mathrm{~h}$ postinjection). The respective agent was intravenously injected into the mice through the tail vein every 2 days. Every time after nanomedicine administration, $808 \mathrm{~nm}$ NIR laser irradiation was performed. The mice were observed daily for clinical symptoms and the tumor sizes were measured by a caliper every other day and calculated as: volume $=($ tumor length $) \times(\text { tumor width })^{2} / 2$. After treatment for 15 days, the mice were sacrificed to collect the tumor for H\&E staining. Morphological changes were observed under a microscope.

\section{In vivo biosafety}

On the 14th day after treatment with DOX-NPs, the mice were sacrificed and blood samples were collected into tubes containing $1.5 \mathrm{mg} / \mathrm{mL} \mathrm{K}_{2}$ EDTA for complete blood cell count. Plasma was separated into cryotubes and stored at $80^{\circ} \mathrm{C}$ until blood chemistry analysis.

\section{Statistical analysis}

Quantitative data are expressed as mean \pm standard deviation (SD) and analyzed using Student's $t$-test. $P$-values $<0.05$ were considered statistically significant.

\section{Results and discussion Preparation and characterization of DOX-NPs}

The protocol for the synthesis of DOX-NPs is shown in Figure 2. The inherent hydrophobicity limits the use of CNTs. ${ }^{33}$ To overcome this problem, carboxyl $(-\mathrm{COOH})$ group was introduced into CNTs. CNTs-COOH were oxidized using acid mixture (nitric acid:hydrochloric acid =3:1) as reported before. After oxidation, the CNTs possessed many active groups, such as $-\mathrm{COOH},-\mathrm{OH}$, and epoxy, enabling the CNTs to have aqueous solubility, neutral $\mathrm{pH}$, and accessibility to further modification. TEM results of CNTs are shown in Figure 3A. Stability and nontoxicity are the essential ingredients for bioapplications. Taking the above elements into consideration, two mild and easily removable reducing agents, ethylene glycol and diethylene glycol, were used to synthesize the CNTs-IONP nanocomposite by chemical deposition of IONP onto CNTs through a hydrothermal reaction (Figure 2). Successful deposition of IONP on CNTs was confirmed by TEM (Figure 3A).

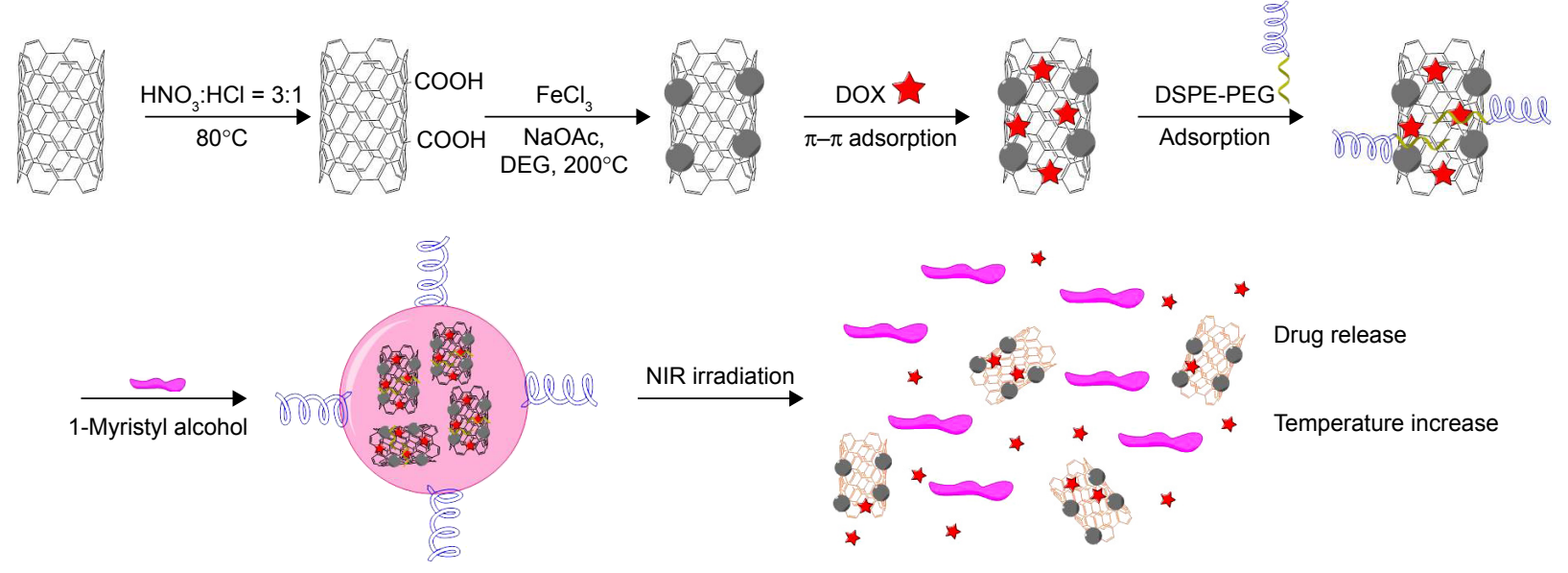

Figure 2 A schematic illustration of the preparation of DOX-NPs.

Note: The red stars indicate DOX (doxorubicin).

Abbreviations: DOX, doxorubicin; DSPE, distearoyl-sn-glycero-3-phosphoethanolamine; NIR, near infrared; NP, nanoparticle; DEG, diethylene glycol. 
The figure shows that IONPs with diameters of 10-20 nm were deposited on CNTs in the CNTs-IONP and CNTsIONP/DOX-PEG samples. DOX is one of the most effective drugs against a wide range of cancers. In this study, it was loaded onto CNTs-IONP through strong $\pi-\pi$ stacking. ${ }^{20}$ The amount of DOX loaded onto CNTs-IONP was $101.24 \mathrm{wt} \%$ $\left(\mathrm{m}_{\mathrm{DOX}}: \mathrm{m}_{\mathrm{CNTS} \text {-IONP }}\right)$. In order to improve the solubility and biocompatibility of CNTs-IONP/DOX, PEGylation was performed by absorption of DSPE-PEG to CNTs to obtain CNTs-IONP/DOX-PEG NPs. The morphology of CNTsIONP/DOX-PEG NPs is shown in Figure 3A. TEM results of CNTs-IONP/DOX-PEG NPs, CNTs, and IONP showed that the size of CNTs-IONP/DOX-PEG NPs was smaller than that of CNTs-IONP NPs (Figure 3A). The PEGylation led to better dispersion in water. Finally, the NPs were encapsulated by 1-MA. After encapsulation, we found the NPs tended to form monodisperse aggregates in the size range of 100-200 nm with a ball-like structure (Figure 3A). From the figure, we can clearly see that the CNTs-IONP/DOX-PEG NPs were successfully encapsulated by 1-MA.

The particle size and the zeta potential of DOX-NPs were determined using DLS and NTA. The DLS results showed
A
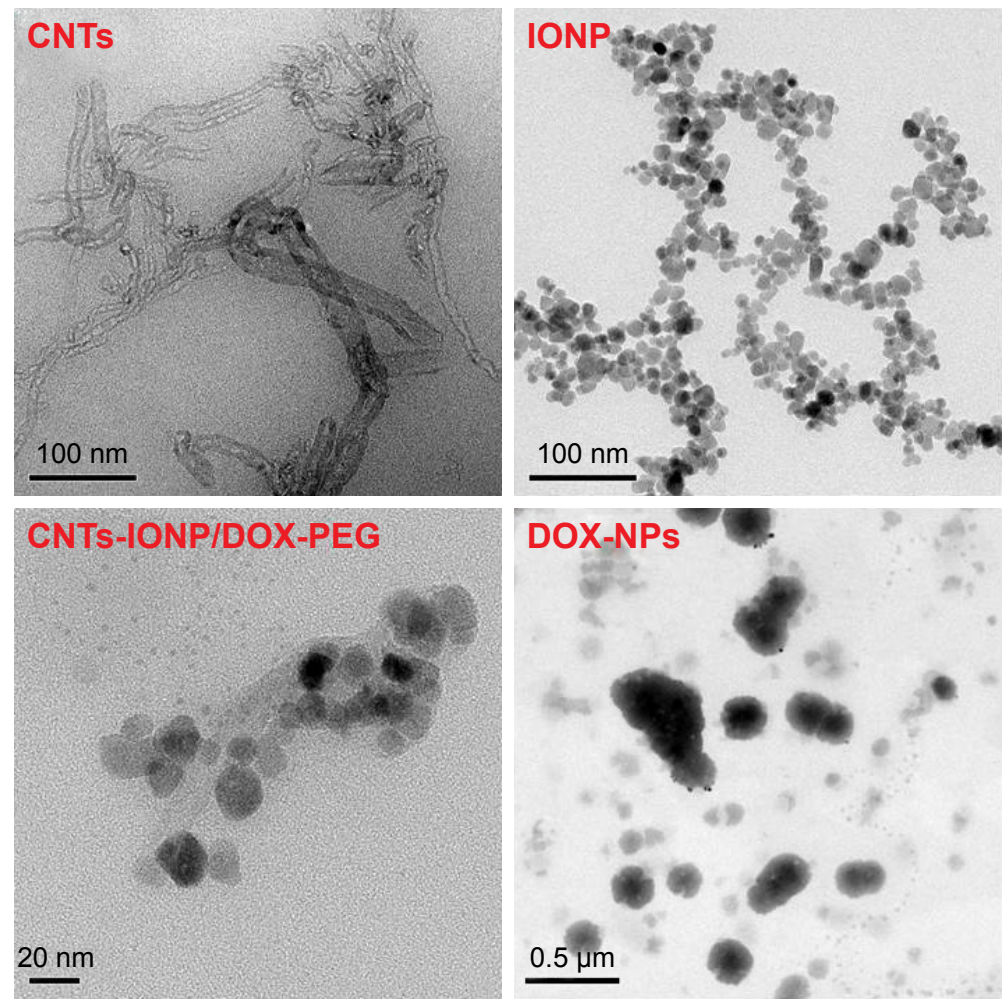

B

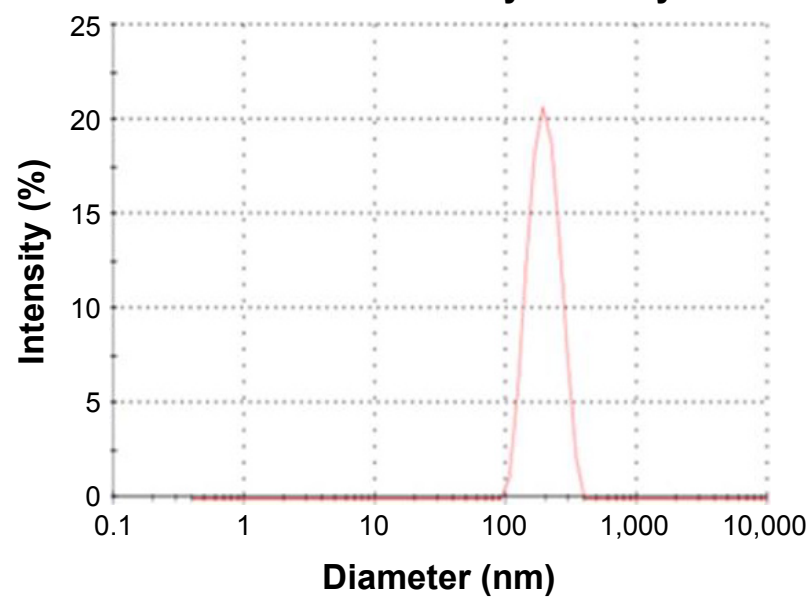

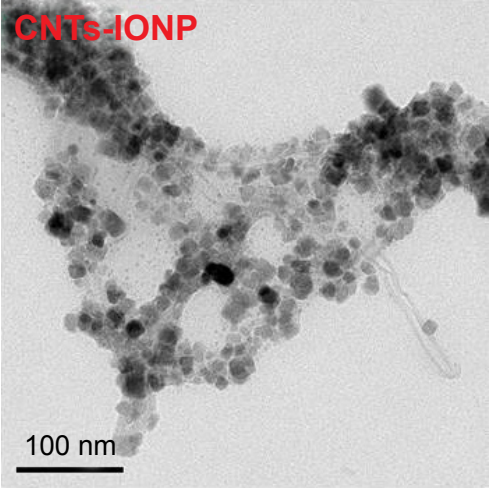

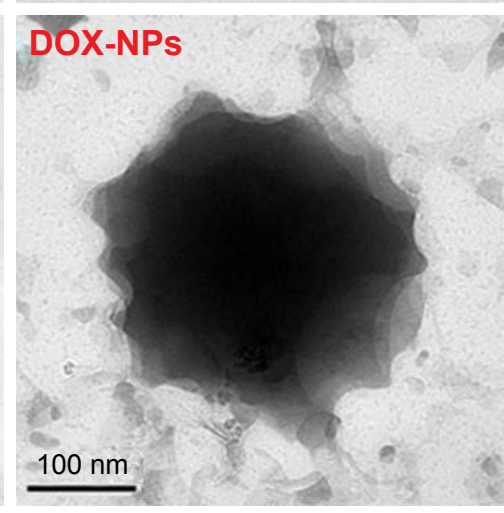

Zeta potential distribution

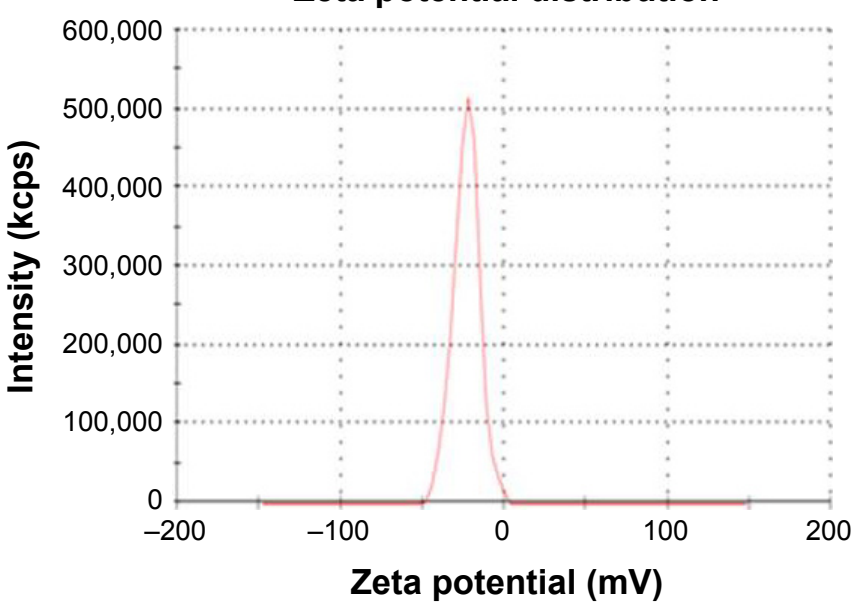

Figure 3 (Continued) 

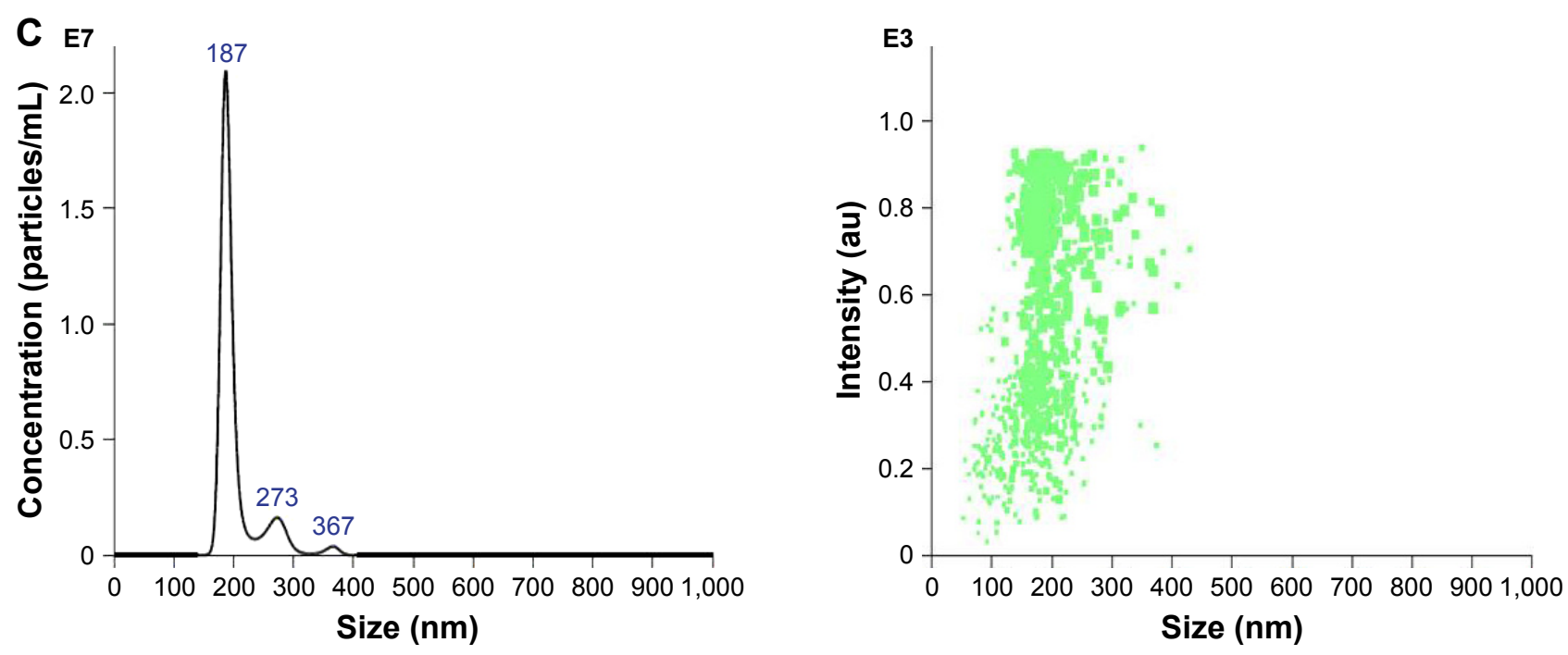

Figure 3 Characterization of DOX-NPs.

Notes: (A) TEM images of CNTs, IONP, CNTs-IONP, CNTs-IONP/DOX-PEG NPs, and DOX-NPs. (B) DLS analysis of DOX-NPs showing an average size distribution around $198 \mathrm{~nm}$ and a zeta potential around $-19.6 \mathrm{mV}$. (C) NTA of DOX-NPs shows that $>90 \%$ of the DOX-NPs were around $200 \mathrm{~nm}$.

Abbreviations: CNTs, carbon nanotubes; DLS, dynamic light scattering; DOX, doxorubicin; IONP, iron oxide nanoparticle; NP, nanoparticle; NTA, nanotracing analysis; TEM, transmission electron microscopy.

that DOX-NPs had an average size of $198.2 \pm 21 \mathrm{~nm}$, and the zeta potential was $-19.6 \pm 3.2 \mathrm{mV}$ (Figure 3B). From the results of NTA, we can clearly see that more than $90 \%$ of the DOX-NPs were around $200 \mathrm{~nm}$ (Figure 3C), and this result was also confirmed by DLS and TEM.

DOX-NPs displayed strong magnetic property. Photos of DOX-NPs in water with and without a magnet clearly demonstrated its magnetic properties. When placed beside a magnet, the DOX-NPs were rapidly attracted by the magnet, leaving the solution colorless (Figure 4A). The magnetization hysteresis loop further indicated the superparamagnetic nature of DOX-NPs (Figure 4B), and the magnetic property of DOX-NPs could be used for the magnetic targeting in vivo. Furthermore, IONPs have been approved by the Food and Drug Administration for use as a $\mathrm{T}_{2}$ contrast agent in MRI. In this study, DOX-NPs could also act as a $\mathrm{T}_{2}$ contrast agent for MRI owing to the presence of IONPs inside DOX-NPs. $\mathrm{T}_{2}$-weighted MR images (Figure 4C) of DOX-NP solutions acquired on a $3 \mathrm{~T}$ MR scanner revealed the concentrationdependent darkening effect (Figure 4C). The MR images of IONP and CNTs-IONP are shown in Figure S1.

\section{"Off-on" state of DOX-NPs \\ "Off-on" photothermal effects}

Next, we investigated the "on" state of DOX-NPs upon irradiation with an $808 \mathrm{~nm}$ NIR laser with a power density of $2 \mathrm{~W} / \mathrm{cm}^{2}$. Firstly, we investigated the "off-on" photothermal effect of DOX-NPs. After NIR irradiation for $6 \mathrm{~min}$, the temperature of DOX-NPs obviously increased to $16.3^{\circ} \mathrm{C}$ when the concentration was $15 \mu \mathrm{g} / \mathrm{mL}$. The temperature increase also occurred in an NIR irradiation time- and particle concentration-dependent manner (Figure 5A). The temperature of water increased to only $1.3^{\circ} \mathrm{C}$, revealing that DOX-NP was an effective photothermal agent in
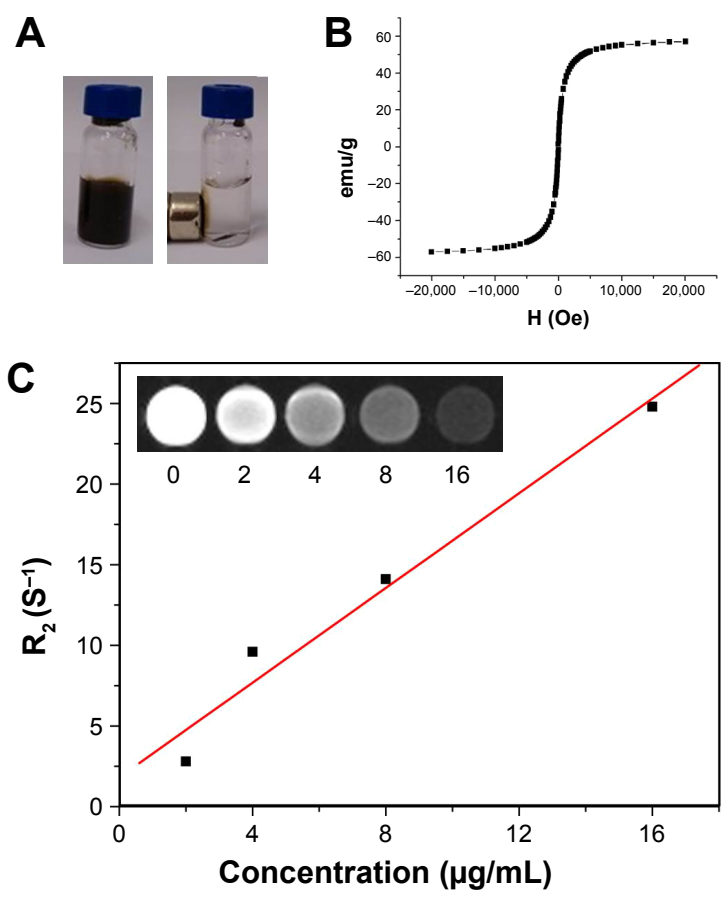

Figure 4 Magnetic properties of DOX-NPs.

Notes: (A) Photos of DOX-NPs in water with and without a magnet. (B) Magnetization loops of DOX-NPs. (C) $T_{2}$ relaxation rates $\left(R_{2}\right)$ of DOX-NP solutions at different concentrations. (Inset) $\mathrm{T}_{2}$-weighted MR images of DOX-NP solutions at different concentrations in $\mu \mathrm{g} / \mathrm{mL}$.

Abbreviations: DOX, doxorubicin; MR, magnetic resonance; NPs, nanoparticles. 

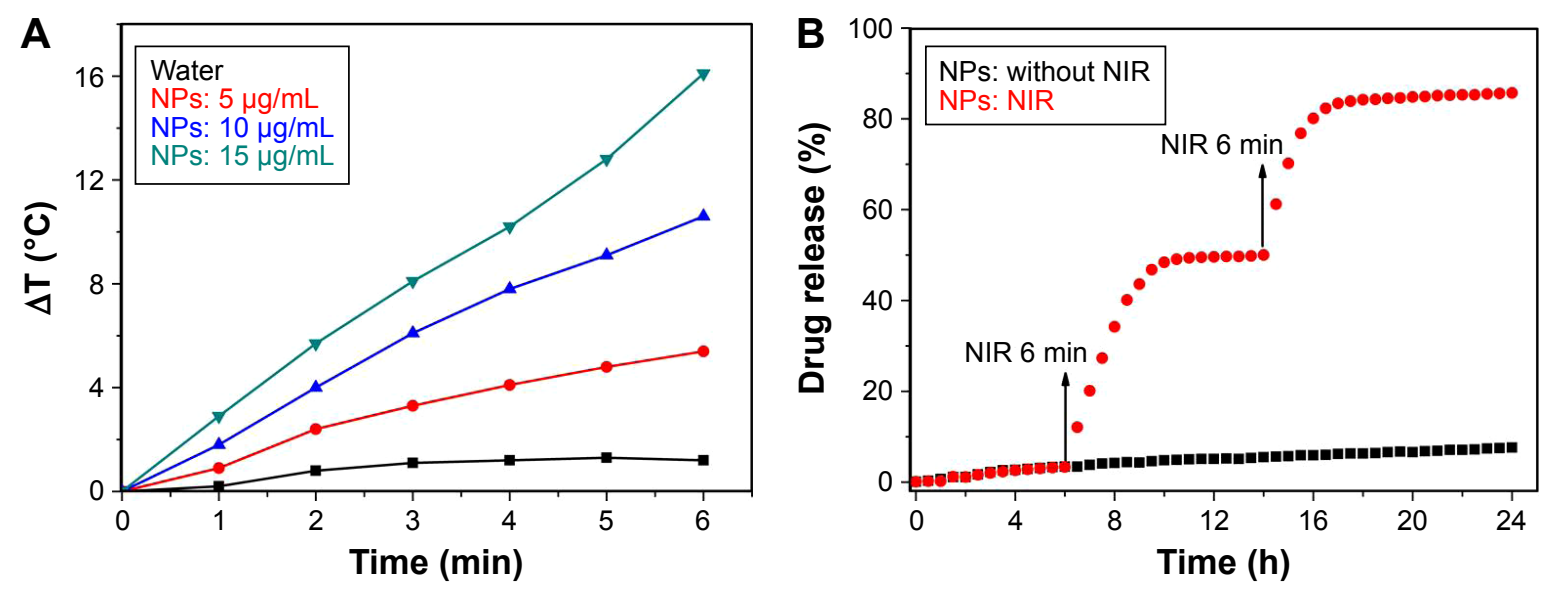

Figure 5 "Off-on" state of DOX-NPs.

Notes: (A) Temperature increase of DOX-NPs during continuous radiation with NIR at a power density of $2 \mathrm{~W} / \mathrm{cm}^{2}$ for $6 \mathrm{~min}$. (B) DOX release from DOX-NPs (NIR radiation at $808 \mathrm{~nm}, 2 \mathrm{~W} / \mathrm{cm}^{2}, 6 \mathrm{~min}$ ) at 6 and $\mathrm{I} 4 \mathrm{~h}$.

Abbreviations: DOX, doxorubicin; NIR, near infrared; NPs, nanoparticles.

cancer therapy. Results revealed an obvious "off-on" photothermal effect controlled by NIR laser.

\section{"Off-on" DOX release}

Since CNTs-IONP/DOX NPs were encapsulated in 1-MA, which could melt when the ambient temperature was over $42^{\circ} \mathrm{C}$, DOX-NP was also expected to display temperatureresponsive "off-on" drug release. Together with the high efficacy of photothermal effect of DOX-NPs upon NIR radiation, DOX-NP was further expected to show precisely NIR-controlled drug release ("off" or "on" state). To test this idea, NIR radiation ( $808 \mathrm{~nm}, 2 \mathrm{~W} / \mathrm{cm}^{2}, 6 \mathrm{~min}$ ) was applied at 6 and $14 \mathrm{~h}$. As can be seen in Figure 5B, a rapid increase in the release of DOX from DOX-NPs occurred upon NIR irradiation, and the DOX release slowed significantly when the NIR irradiation was switched off. After the first "on" state for $4 \mathrm{~h}$, the cumulative release of loaded DOX increased from $3.3 \%$ to $48.4 \%$, while only $1.6 \%$ of DOX ( $48.4 \%-50.0 \%$ ) was released during the subsequent $4 \mathrm{~h}$ of "off" state. After the second "on" state for $4 \mathrm{~h}$, the DOX release was further increased rapidly (a $34.2 \%$ [from $50.0 \%$ to $84.2 \%$ ] increase). The DOX release from DOX-NPs with "on" state over $24 \mathrm{~h}$ approached $85.7 \%$. In sharp contrast, DOX-NPs with "off" state over $24 \mathrm{~h}$ displayed a DOX release of 7.6\% (Figure 5B). Results of DOX release thus showed an obvious "off-on" DOX release controlled by NIR laser.

\section{Cellular uptake}

To evaluate the enhanced cellular internalization of DOX-NPs induced by magnet, we tracked the internalization of DOX in cells through the localization of the DOX signal (red fluorescence). The intracellular DOX-NP distribution is shown in
Figure 6. From the figure, we can see that DOX-NPs accumulated in the magnet area, where, after incubation for $4 \mathrm{~h}$, a large amount of DOX signals was observed in the cell cytoplasm. While in the external magnetic area, only a little amount of DOX signals was observed, indicating the cellular internalization of DOX-NPs was enhanced by the magnet. These results also showed the magnetic targeting property of DOX-NPs in cultured 4T1 cells. As we know, the nanoscaled DDS could accumulate in the tumor tissue by EPR effect. Combining the EPR effect of the nanoscaled DDS and the magnetic-targeting ability, the developed DDS in this study could efficiently enter the tumor tissue. However, the developed DDS could not target small lesions or metastases and could only target the solid tumors in vivo. Compared with the target-specific nanoscaled DDSs, the speed of cellular uptake of the developed DDS is considered slow, and the amount of the DDS that entered into cancer cells was less than that of the target-specific nanoscaled DDSs. So, in the next study, the developed DDS will be further modified by a tumor cell targeting group, such as folic acid, RGD, NGR peptides, and so on.

\section{"Off-on" state of DOX-NPs in 4TI cells}

We next investigated the "off-on" state of DOX-NPs in 4T1 cells. DOX-NPs were incubated with $4 \mathrm{~T} 1$ cells for $4 \mathrm{~h}$ with a magnet (magnetic field intensity $0.3 \mathrm{~T}$ ) placed under the center of the culture dish. Then, we investigated the "on" state of DOX-NPs in cells upon irradiation with $808 \mathrm{~nm}$ laser at a power density of $2 \mathrm{~W} / \mathrm{cm}^{2}$ for $6 \mathrm{~min}$ ("on" state). In Figure 7, it can be seen that the free DOX could quickly diffuse into the cell nucleus; the intracellular DOX in the cytosol was rapidly transported to the nucleus and avidly bound to the chromosomal DNA. ${ }^{34}$ However, in the DOX-NPs "off" state 


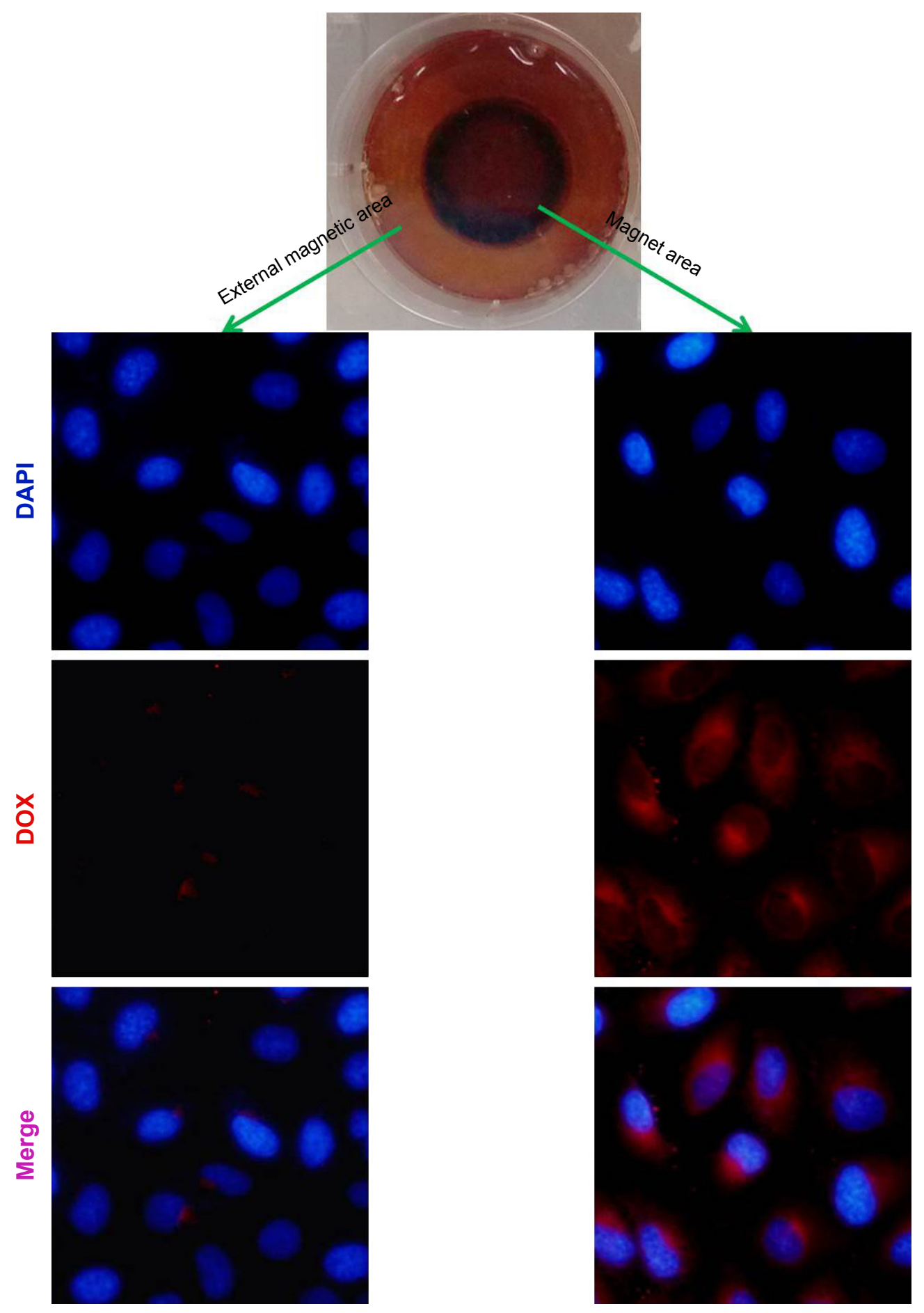

Figure 6 Confocal images of $4 \mathrm{TI}$ cells incubated with DOX-NPs with a magnet (magnetic field intensity $0.3 \mathrm{~T}$ ) placed under the center of the culture dish for $4 \mathrm{~h}$. Abbreviations: DOX, doxorubicin; NPs, nanoparticles.

group (without NIR), almost all of the DOX was observed in the cell cytoplasm and only a very small part of DOX was observed in the cell nucleus (Figure 7), indicating that DOX-NPs could not enter into the cell nucleus. When the DOX-NPs were in "off" state, DOX was encapsulated in the NPs and was not released from the DOX-NPs. In the case of DOX-NPs in "on" state (with NIR), DOX was observed in the cell nucleus (Figure 7), suggesting that after NIR irradiation ("on" state), DOX was released from DOX-NPs, and the released DOX quickly diffused into the cell nucleus. According to previous studies, DDSs enter into tumor cells through endocytosis and are trapped in lysosomes in the cytosol. ${ }^{35,36}$ DOX-NPs should were trapped in the lysosomes; but when the NPs were "on", a large amount of heat was generated 


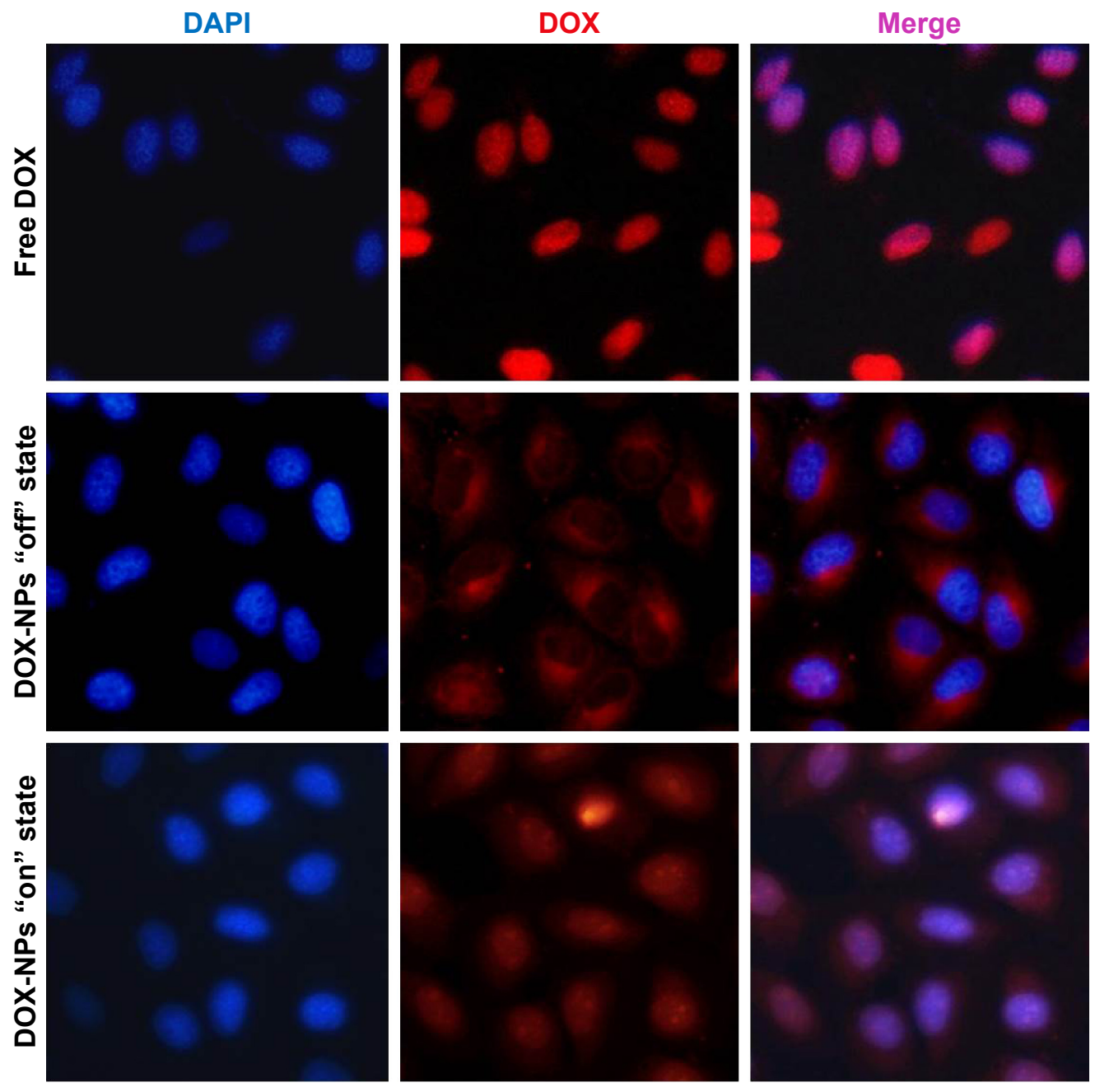

Figure 7 Confocal images of 4TI cells incubated with DOX and DOX-NPs with "off" or "on" state (under a 0.3 T magnet). Abbreviations: DOX, doxorubicin; NPs, nanoparticles.

(Figure 5A), which led to the rupture of the lysosome and the release of NPs from the lysosome.

\section{Antitumor effects of DOX-NPs in vitro}

The cell viabilities of DOX-NPs in "off" or "on" state are shown in Figure 8A. The blank NPs (without loading DOX) showed minimal decrease in cell viability $(<10 \%)$ at a concentration of $30 \mu \mathrm{g} / \mathrm{mL}$, suggesting the blank NPs possess very low toxicity. While in the case of blank NPs $+\mathrm{M}+\mathrm{NIR}$ (with a magnet and irradiated with NIR), the cell viability decreased to $56.7 \%$, indicating that under a magnet, more NPs could enter into the cells and after NIR, a lot of heat was generated, leading to the death of cells. Compared with DOX-NPs + M ("off" state, 76.3\%), DOX-NPs + M + NIR ("on" state) had a cell viability of $21.6 \%$, showing the "off-on" state of DOX-NPs. When the DOX-NPs were in "on" state, on one hand, a lot of heat was generated by CNTs, leading to hyperthermia effect to 4T1 cells; on the other hand, DOX was released from the
DOX-NPs, leading to the chemotherapeutic effect to 4T1 cells. The combination therapy (hyperthermia and chemotherapy) of DOX-NPs ("on" state) was effective to 4T1 cells.

Besides, when the DOX-NPs were in "off" state, no heat was generated and no DOX was released, this could decrease the side effects to normal tissues. To test this, cytotoxicity studies were performed using mouse hepatocytes cells (AML 12), and the results are shown in Figure 8B. Compared with DOX, DOX-NPs group ("off” state) greatly decreased the cytotoxicity of DOX to AML 12 cells, suggesting DOXNPs could significantly decrease the side effect of DOX to liver cells.

\section{MRI and biodistribution of DOX-NPs in vivo}

The high in vitro MRI contrast performance of DOX-NPs inspired us to pursue their applicability for in vivo trials. In our study, we conducted whole-body animal imaging by 

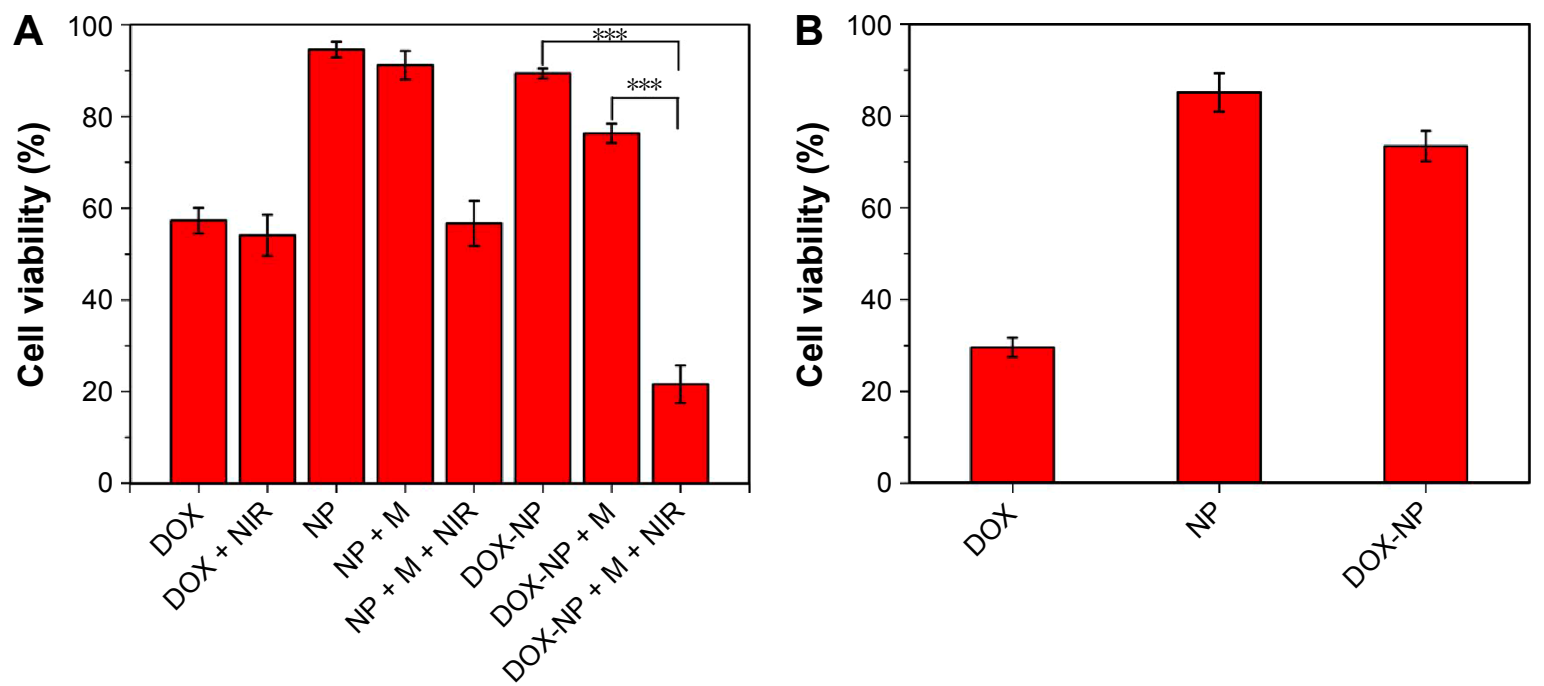

Figure 8 (A) Cell viability of 4TI cells after different treatments for 24 h. (B) Cytotoxicities of DOX, blank NPs, and DOX-NPs to mouse hepatocytes cells (AML I2). Data presented are mean $\pm S D(n=6)$. $* * * P<0.01$.

Abbreviations: DOX, doxorubicin; M, magnet; NIR, near infrared; NP, nanoparticle; SD, standard deviation.

intravenously injecting DOX-NPs $(0.2 \mathrm{~mL}$, DOX: $5 \mathrm{mg} / \mathrm{kg}$, NPs: $15 \mathrm{mg} / \mathrm{kg}$ ) into 4T1 tumor-bearing mice with or without a magnet (magnetic field intensity $0.3 \mathrm{~T}$ ) glued on the tumor site. MRI was conducted on a $3 \mathrm{~T}$ clinical MRI scanner $8 \mathrm{~h}$ after the injection. The results are shown in Figure 9A. An obvious darkening effect was observed in $\mathrm{T}_{2}$-weighted MR images of the tumor (Figure 9A), and the darkening effect in the tumor after injection of DOX-NPs was also confirmed
A
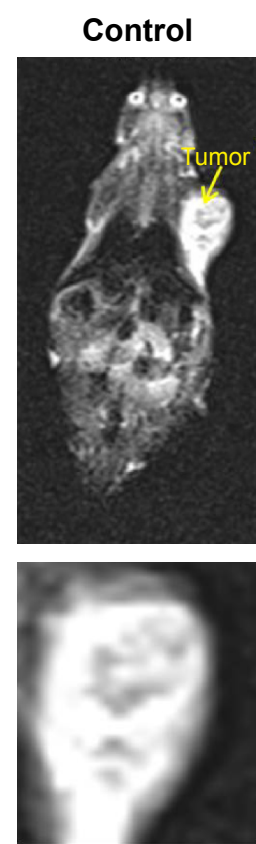

DOX-NPs + M
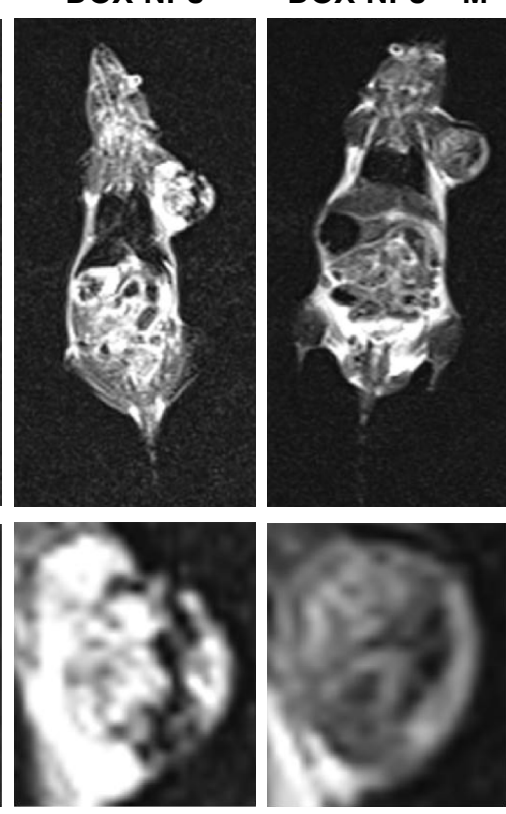

Enlarged view of tumor

B
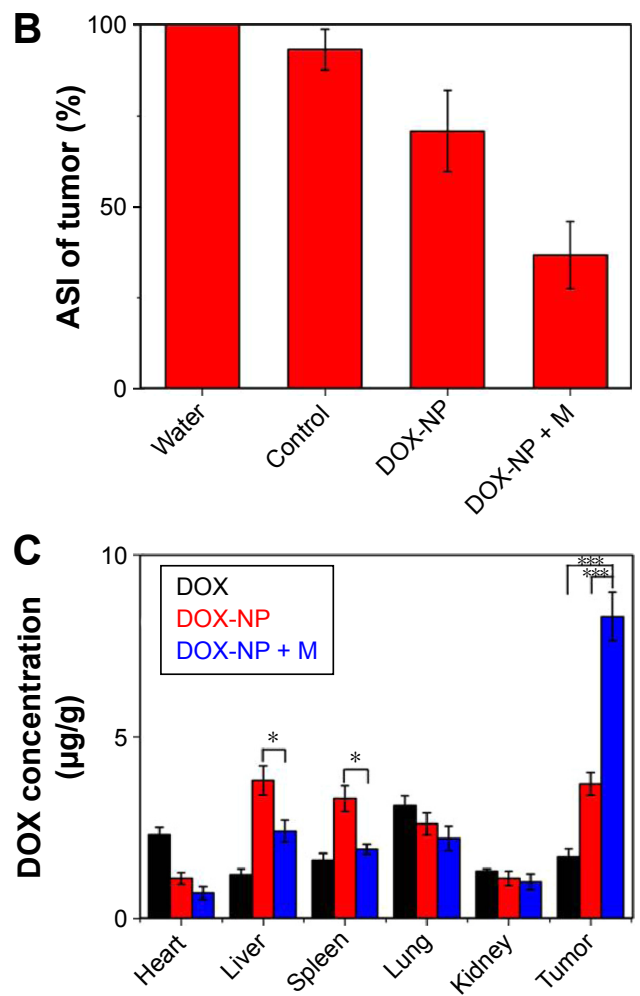

Figure 9 (A) In vivo $\mathrm{T}_{2}$-weighted MR images after injection of DOX-NPs with or without a magnet glued onto the tumor site for $8 \mathrm{~h}$. (B) ASI in the tumor after injection of DOX-NPs with or without a magnet glued onto the tumor site for $8 \mathrm{~h}$. (C) Biodistribution of tumor-bearing mice treated with DOX and DOX-NPs with or without a magnet. Data presented are mean $\pm S D(n=3)$. $* P<0.05 ; * * * P<0.01$.

Abbreviations: ASI, average signal intensity; DOX, doxorubicin; M, magnet; MRI, magnetic resonance imaging; NIR, near infrared; NP, nanoparticle; SD, standard deviation. 
quantitatively (Figure 9B). Compared with the average signal intensity (ASI) of the tumor in the control group (93.2\%), the DOX-NPs group showed a decrease in ASI of the tumor by $70.8 \%$, indicating DOX-NPs could accumulate in the tumor site after injection by EPR effect. The large MRI signal change $(\sim 22 \%)$ could point to the specific position of the tumor, suggesting DOX-NPs could be used as a tumor diagnostic agent. In the case of DOX-NPs $+\mathrm{M}$ (with a $0.3 \mathrm{~T}$ magnet glued on the tumor site), the ASI of tumor decreased by $36.7 \%$ and showed a significant difference from the DOX-NPs (without magnet) group, suggesting the magnetic targeting property of DOX-NPs.
A

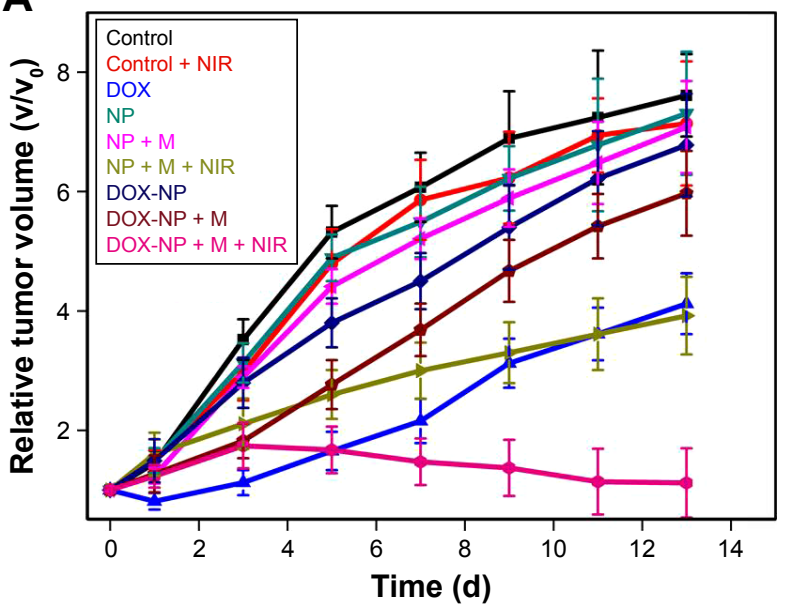

B

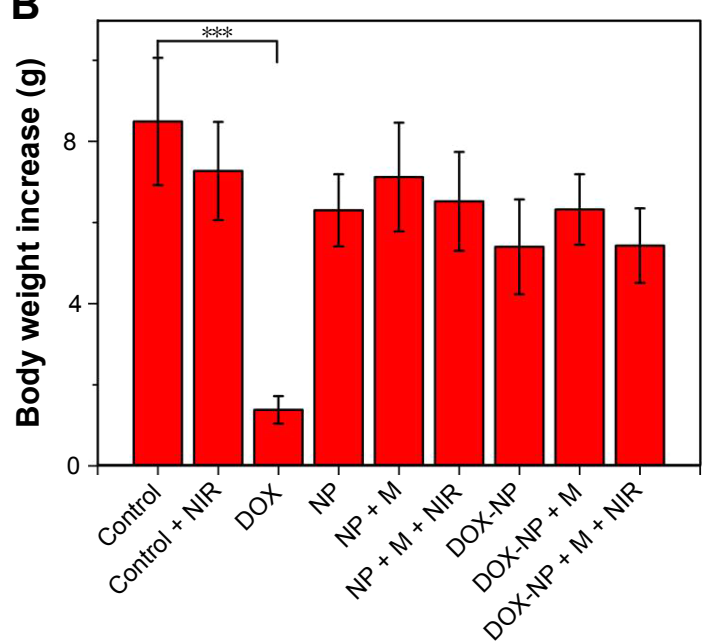

C
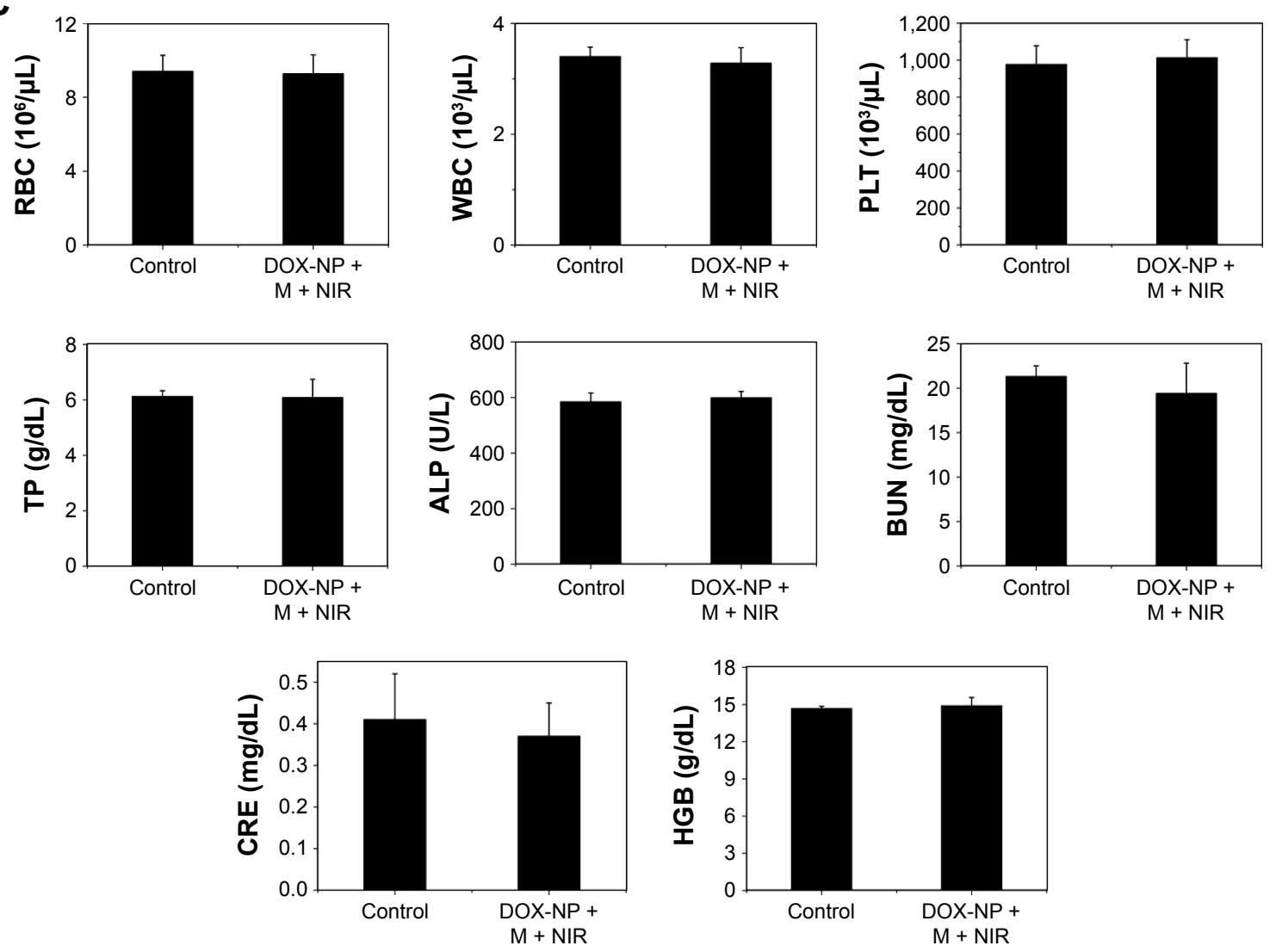

Figure 10 (A) Tumor growth in mice from different treatment groups within 14 days of implantation. (B) Graphs of the mean body weights of mice receiving different treatments. (C) The complete blood panel data from DOX-NPs + M + NIR-treated mice and the control group: RBC, WBC, PLT, TP, ALP, BUN, CRE, and HGB. Data presented are mean $\pm S D(n=6)$. *** $P<0.01$.

Abbreviations: ALP, alkaline phosphatase; BUN, blood urea nitrogen; CRE, creatinine; DOX, doxorubicin; HGB, hemoglobin; M, magnet; NIR, near infrared; NPs, nanoparticles; PLT, platelet count; RBC, red blood cells; SD, standard deviation; TP, total protein; WBC, white blood cells. 
To further investigate the biodistribution of DOX-NPs, the DOX concentrations were examined in the main tissues (heart, liver, spleen, lung, kidney, and tumor) $8 \mathrm{~h}$ after the injection. The results are shown in Figure 9C. The DOX levels in the tumors of the DOX-NPs + M group $(8.3 \mu \mathrm{g} / \mathrm{g})$ were 4.9 and 2.2-fold higher than those of the DOX group $(1.7 \mu \mathrm{g} / \mathrm{g})$ and the DOX-NPs group $(3.7 \mu \mathrm{g} / \mathrm{g})$, respectively. The results were also confirmed by the results of MRI. Furthermore, compared with the DOX-NPs (without magnet) group, the DOX levels in the liver and spleen of the DOX-NPs + M group were significantly decreased (Figure 9C). Magnetic targeting could decrease the high biodistribution of DOX-NPs in RES organs (liver and spleen), and this could also decrease the side effects of DOX-NPs to endothelial reticular system organs.

\section{In vivo antitumor effect}

We extended the studies from in vitro to in vivo to investigate the regression efficacy in tumor growth, which was monitored in terms of tumor volume change (Figure 10A). In the groups treated with saline only, saline + NIR, and blank NPs, the mice were closely monitored for the continuous growth of tumor, which grew $\sim 7$ times larger on day 15 than it was initially. The blank NPs $+\mathrm{M}+\mathrm{NIR}$ group showed a relative tumor volume $\left(\mathrm{V} / \mathrm{V}_{0}\right)$ of 3.92 , indicating the hyperthermia effect of the blank NPs. To further understand the therapeutic efficacy of hyperthermia, the thermal effect of NPs active by NIR at the tumor site was investigated (Figure 11). After NIR irradiation of the tumor site for $6 \mathrm{~min}$, the temperature at the tumor site in DOX-NPs $+\mathrm{M}+\mathrm{NIR}$ group increased significantly by $17.1^{\circ} \mathrm{C}$ (from $32.0^{\circ} \mathrm{C}$ to $49.1^{\circ} \mathrm{C}$ ), explaining the efficacy of hyperthermia in vivo. In the case of DOX only group, minor suppression of the tumors was seen as the tumors grew $\sim 4$ times larger after 15 days. On the contrary, in DOX-NPs + M + NIR ("on" state) group, the tumor grew no larger in 15 days. On day 15, DOX-NPs in "off" state (without NIR) showed a V/V $\mathrm{V}_{0}$ of 5.97; in contrast, the tumor growth was totally inhibited by DOX-NPs + M + NIR in "on" state (1.12) (Figure 10A), indicating the obvious
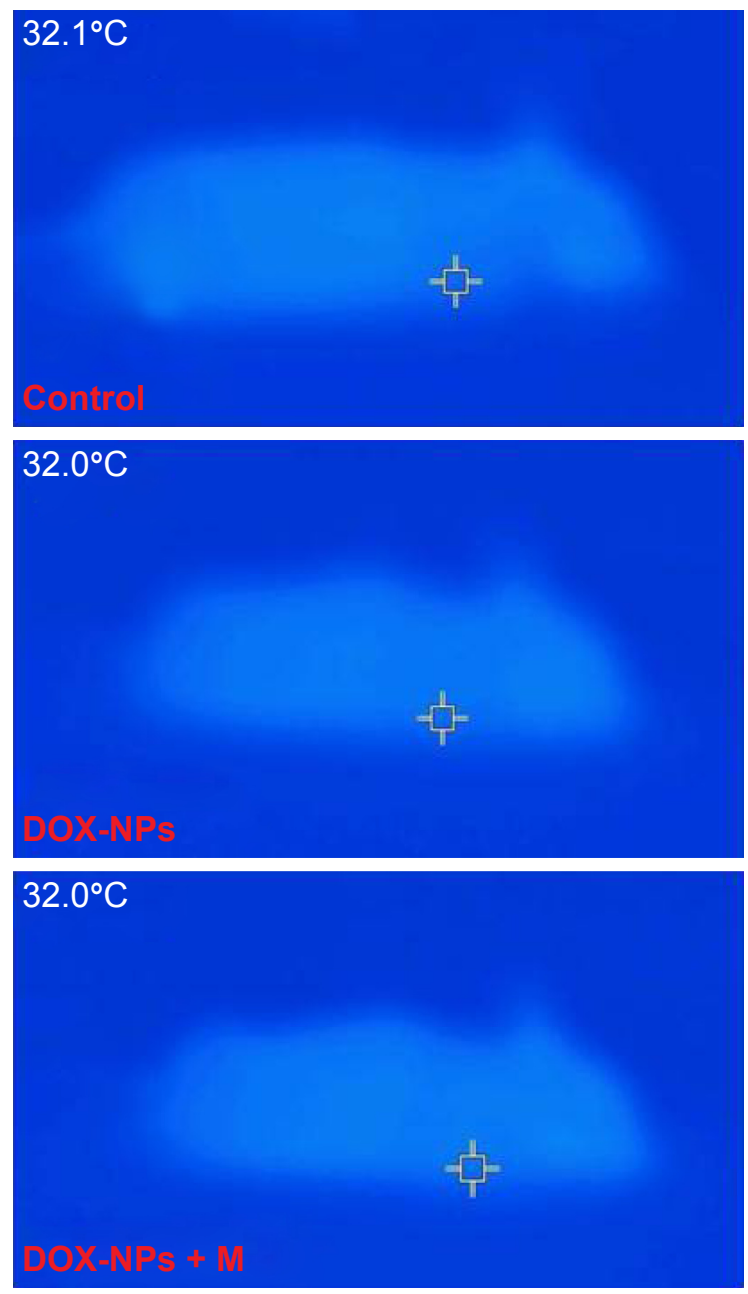
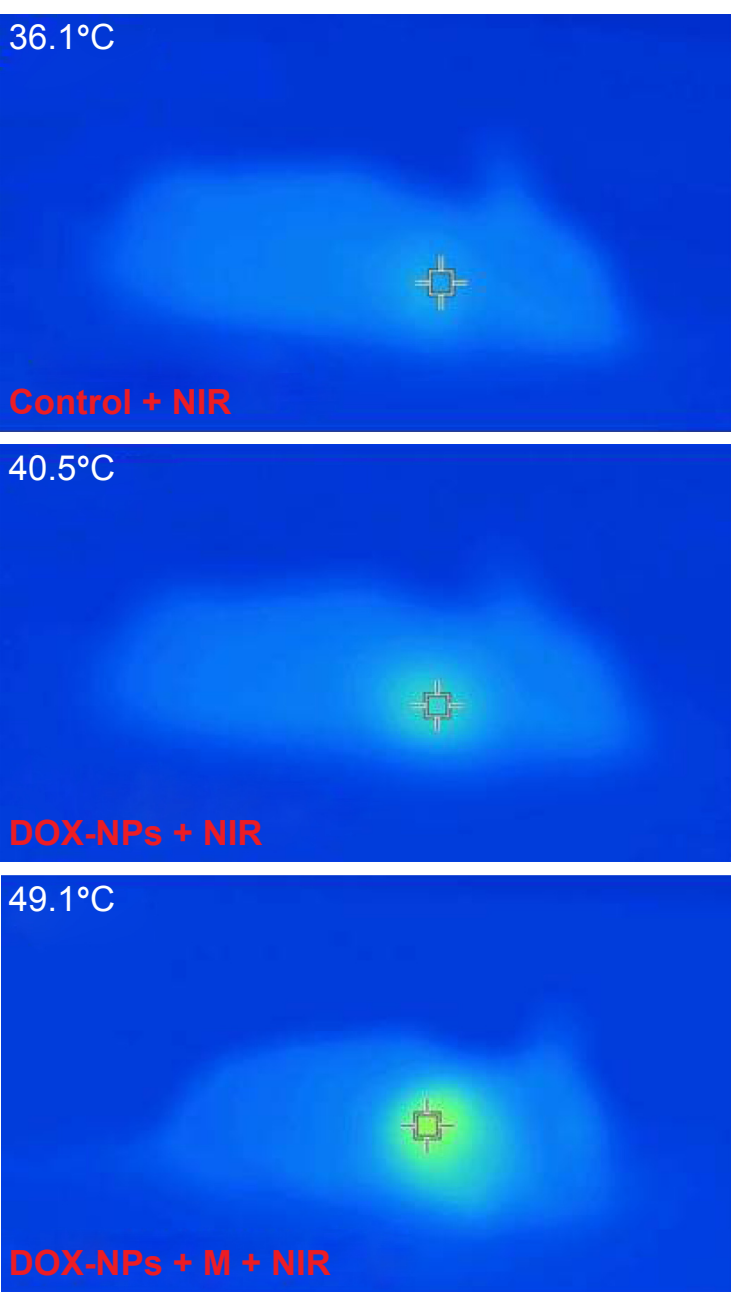

Figure I I IR thermal images of tumor-bearing mice.

Abbreviations: DOX, doxorubicin; M, magnet; NIR, near infrared; NPs, nanoparticles. 

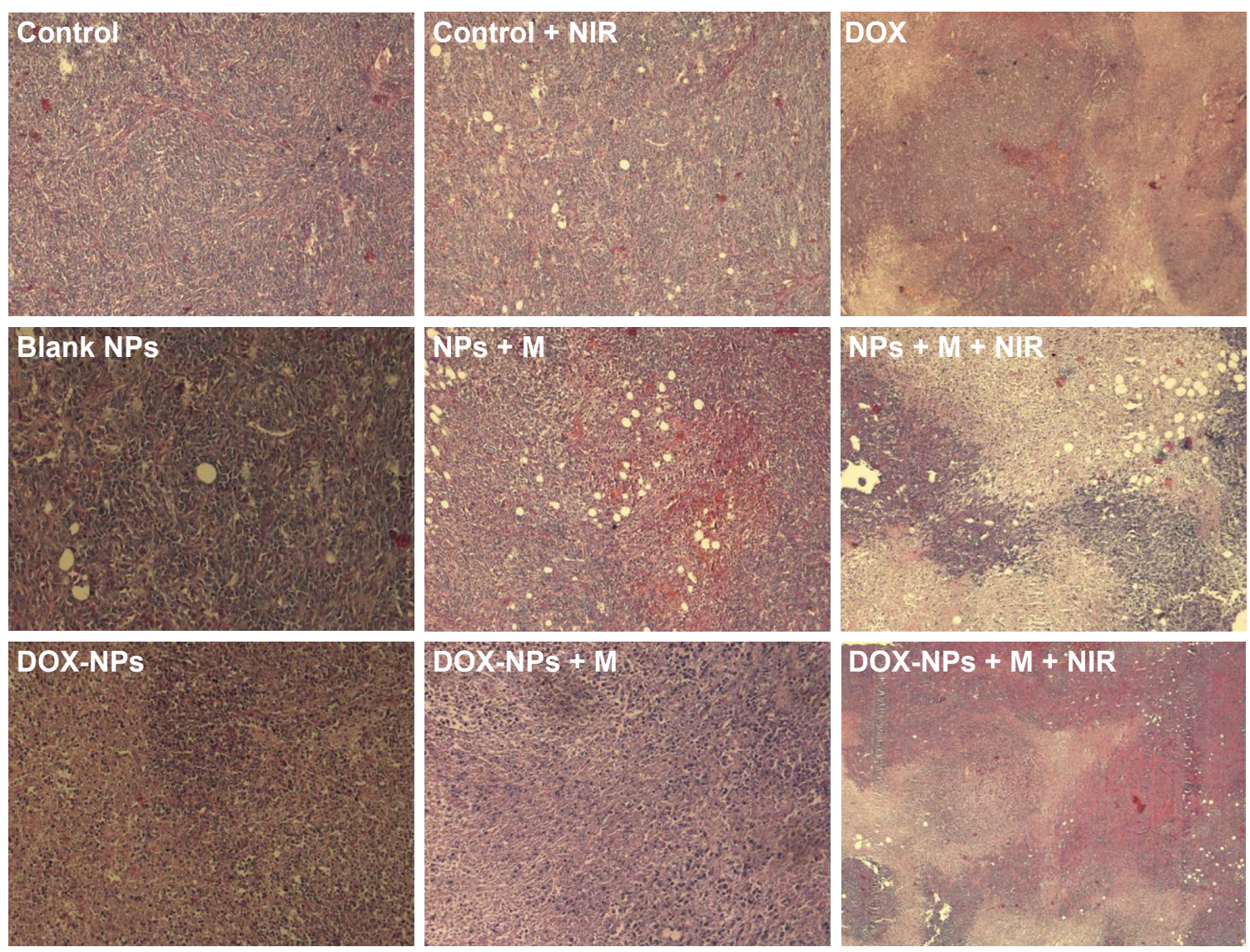

Figure 12 H\&E staining images of tumors of 4TI tumor-bearing mice under different treatments.

Abbreviations: DOX, doxorubicin; H\&E, hematoxylin and eosin; M, magnet; NIR, near infrared; NPs, nanoparticles.

"off-on" state in vivo and the "on" state of NPs resulted in the effectiveness of combination treatment (hyperthermia and chemotherapy) and, thus, suppression of tumor growth. The therapeutic efficacy of DOX-NPs was also evaluated in the images of histological tissues stained with H\&E. The tumor-bearing mice treated with DOX-NPs + M + NIR "on" state displayed extensive cell death in the tumor tissues (Figure 12). The H\&E staining results are consistent with the in vivo antitumor effects.

\section{In vivo biosafety}

Potential in vivo toxicity has always been a great concern in the development of nanodrugs. Besides measuring the body weights of mice in each cohort (Figure 10B), the complete blood panel data of red blood cells, white blood cells, platelet count, the blood levels of total protein, alkaline phosphatase, blood urea nitrogen, creatinine, and hemoglobin of the DOX-NP + M + NIR group and control group were also obtained. The results are shown in Figure 10C. No observable toxicity was noted in blood analysis. All these results demonstrated that DOX-NP $+\mathrm{M}+\mathrm{NIR}$ showed high biosafety for the combination tumor treatment and presented no significant side effects to the $4 \mathrm{~T} 1$ tumor-bearing mice.

\section{Conclusion}

In conclusion, this study shows the feasibility of using multifunctional DOX-loaded NPs with "off-on" state for effective treatment of cancer. DOX-NPs showed an obvious "off-on" effect controlled by NIR light in vitro and in vivo. In the in vivo and in vitro studies, DOX-NPs exhibited MRI ability, magnetic targeting property, high biosafety, and high antitumor combined therapeutic efficacy (hyperthermia combined with chemotherapy).

\section{Disclosure}

The authors report no conflicts of interest in this work.

\section{References}

1. Settleman J. Cancer: bet on drug resistance. Nature. 2016;529(7586): 289-290.

2. Shi J, Wang B, Chen Z, et al. A multi-functional tumor theranostic nanoplatform for MRI guided photothermal-chemotherapy. Pharm Res. 2016;33(6):1472-1485. 
3. Shi J, Chen Z, Wang L, et al. A tumor-specific cleavable nanosystem of PEG-modified C60@Au hybrid aggregates for radio frequencycontrolled release, hyperthermia, photodynamic therapy and X-ray imaging. Acta Biomater. 2016;29:282-297.

4. Shi J, Chen Z, Wang B, Wang L, Lu T, Zhang Z. Reactive oxygen species-manipulated drug release from a smart envelope-type mesoporous titanium nanovehicle for tumor sonodynamic-chemotherapy. ACS Appl Mater Interfaces. 2015;7(51):28554-28565.

5. Shi J, Wang L, Gao J, et al. A fullerene-based multi-functional nanoplatform for cancer theranostic applications. Biomaterials. 2014;35(22): 5771-5784.

6. Shi J, Zhang H, Wang L, et al. PEI-derivatized fullerene drug delivery using folate as a homing device targeting to tumor. Biomaterials. 2013; 34(1):251-261.

7. Shi J, Liu Y, Wang L, et al. A tumoral acidic pH-responsive drug delivery system based on a novel photosensitizer (fullerene) for in vitro and in vivo chemo-photodynamic therapy. Acta Biomater. 2014;10(3): 1280-1291.

8. Nguyen LH, Diao HJ, Chew SY. MicroRNAs and their potential therapeutic applications in neural tissue engineering. Adv Drug Deliv Rev. 2015;88:53-66.

9. Xiao W, Zeng X, Lin H, Han K, Jia HZ, Zhang XZ. Dual stimuliresponsive multi-drug delivery system for the individually controlled release of anti-cancer drugs. Chem Commun (Camb). 2015;51(8): 1475-1478.

10. Wang W, Chen L, Xu LP, et al. A free-blockage controlled release system based on the hydrophobic/hydrophilic conversion of mesoporous silica nanopores. Chemistry. 2015;21(6):2680-2685.

11. Sadighian S, Hosseini-Monfared H, Rostamizadeh K, Hamidi M. $\mathrm{pH}$-triggered magnetic-chitosan nanogels (MCNs) for doxorubicin delivery: physically vs chemically cross linking approach. Adv Pharm Bull. 2015;5(1):115-120.

12. Chen MC, Lin ZW, Ling MH. Near-infrared light-activatable microneedle system for treating superficial tumors by combination of chemotherapy and photothermal therapy. ACS Nano. 2016;10(1):93-101.

13. Huang K, Shi B, Xu W, et al. Reduction-responsive polypeptide nanogel delivers antitumor drug for improved efficacy and safety. Acta Biomater. 2015;27:179-193.

14. Ding Y, Wang Y, Opoku-Damoah Y, et al. Dual-functional bio-derived nanoparticulates for apoptotic antitumor therapy. Biomaterials. 2015; 72:90-103.

15. Shaker MA, Younes HM. Photo-irradiation paradigm: mapping a remarkable facile technique used for advanced drug, gene and cell delivery. J Control Release. 2015;217:10-26.

16. Qin Y, Chen J, Bi Y, et al. Near-infrared light remote-controlled intracellular anti-cancer drug delivery using thermo/pH sensitive nanovehicle. Acta Biomater. 2015;17:201-209.

17. Chen H, Di Y, Chen D, et al. Combined chemo- and photo-thermal therapy delivered by multifunctional theranostic gold nanorod-loaded microcapsules. Nanoscale. 2015;7(19):8884-8897.

18. Shi J, Wang L, Zhang J, et al. A tumor-targeting near-infrared lasertriggered drug delivery system based on GO@Ag nanoparticles for chemo-photothermal therapy and X-ray imaging. Biomaterials. 2014; 35(22):5847-5861.

19. Shi J, Ma R, Wang L, et al. The application of hyaluronic acid-derivatized carbon nanotubes in hematoporphyrin monomethyl ether-based photodynamic therapy for in vivo and in vitro cancer treatment. Int $J$ Nanomedicine. 2013;8:2361-2373.
20. Tsai HC, Lin JY, Maryani F, Huang CC, Imae T. Drug-loading capacity and nuclear targeting of multiwalled carbon nanotubes grafted with anionic amphiphilic copolymers. Int J Nanomedicine. 2013;8: 4427-4440.

21. Luo X, Matranga C, Tan S, Alba N, Cui XT. Carbon nanotube nanoreservior for controlled release of anti-inflammatory dexamethasone. Biomaterials. 2011;32(26):6316-6323.

22. Karchemski F, Zucker D, Barenholz Y, Regev O. Carbon nanotubesliposomes conjugate as a platform for drug delivery into cells. J Control Release. 2012;160(2):339-345.

23. Yi D, Zeng P, Wiedmann TS. Magnetic activated release of umbelliferone from lipid matrices. Int J Pharm. 2010;394(1-2):143-146.

24. Deng L, Li Q, Al-Rehili S, et al. Hybrid iron oxide-graphene oxidepolysaccharides microcapsule: a micro-matryoshka for on-demand drug release and antitumor therapy in vivo. ACS Appl Mater Interfaces. 2016; 8(11):6859-6868.

25. Zhao Y, Liang M, Li X, et al. Bioengineered magnetoferritin nanoprobes for single-dose nuclear-magnetic resonance tumor imaging. ACS Nano. 2016;10(4):4184-4191.

26. Guo Z, Gao M, Song M, et al. Superfluorinated PEI derivative coupled with Tc for ASGPR targeted F MRI/SPECT/PA tri-modality imaging Adv Mater. 2016;28(28):5898-5906.

27. Filson CP, Natarajan S, Margolis DJ, et al. Prostate cancer detection with magnetic resonance-ultrasound fusion biopsy: the role of systematic and targeted biopsies. Cancer. 2016;122(6):884-892.

28. Shi J, Yu X, Wang L, et al. PEGylated fullerene/iron oxide nanocomposites for photodynamic therapy, targeted drug delivery and MR imaging. Biomaterials. 2013;34(37):9666-9677.

29. Choi WI, Lee JH, Kim JY, et al. Targeted antitumor efficacy and imaging via multifunctional nano-carrier conjugated with anti-HER2 trastuzumab. Nanomedicine. 2015;11(2):359-368.

30. Wang H, Cao G, Gai Z, Hong K, Banerjee P, Zhou S. Magnetic/ NIR-responsive drug carrier, multicolor cell imaging, and enhanced photothermal therapy of gold capped magnetite-fluorescent carbon hybrid nanoparticles. Nanoscale. 2015;7(17):7885-7895.

31. Kim SM, Chae MK, Yim MS, et al. Hybrid PET/MR imaging of tumors using an oleanolic acid-conjugated nanoparticle. Biomaterials. 2013; 34(33):8114-8121.

32. Wang L, Shi L, Jia X, et al. NIR-/pH-Responsive drug delivery of functionalized single-walled carbon nanotubes for potential application in cancer chemo-photothermal therapy. Pharm Res. 2013;30(11): 2757-2771.

33. Zhao Q, Feng X, Mei S, Jin Z. Carbon-nanotube-assisted high loading and controlled release of polyoxometalates in biodegradable multilayer thin films. Nanotechnology. 2009;20(10):105101.

34. Zhu S, Xu G. Single-walled carbon nanohorns and their applications. Nanoscale. 2010;2(12):2538-2549.

35. Gillies ER, Frechet JM. pH-Responsive copolymer assemblies for controlled release of doxorubicin. Bioconjug Chem. 2005;16(2): 361-368.

36. Nori A, Kopecek J. Intracellular targeting of polymer-bound drugs for cancer chemotherapy. Adv Drug Deliv Rev. 2005;57(4):609-636. 


\section{Supplementary material}
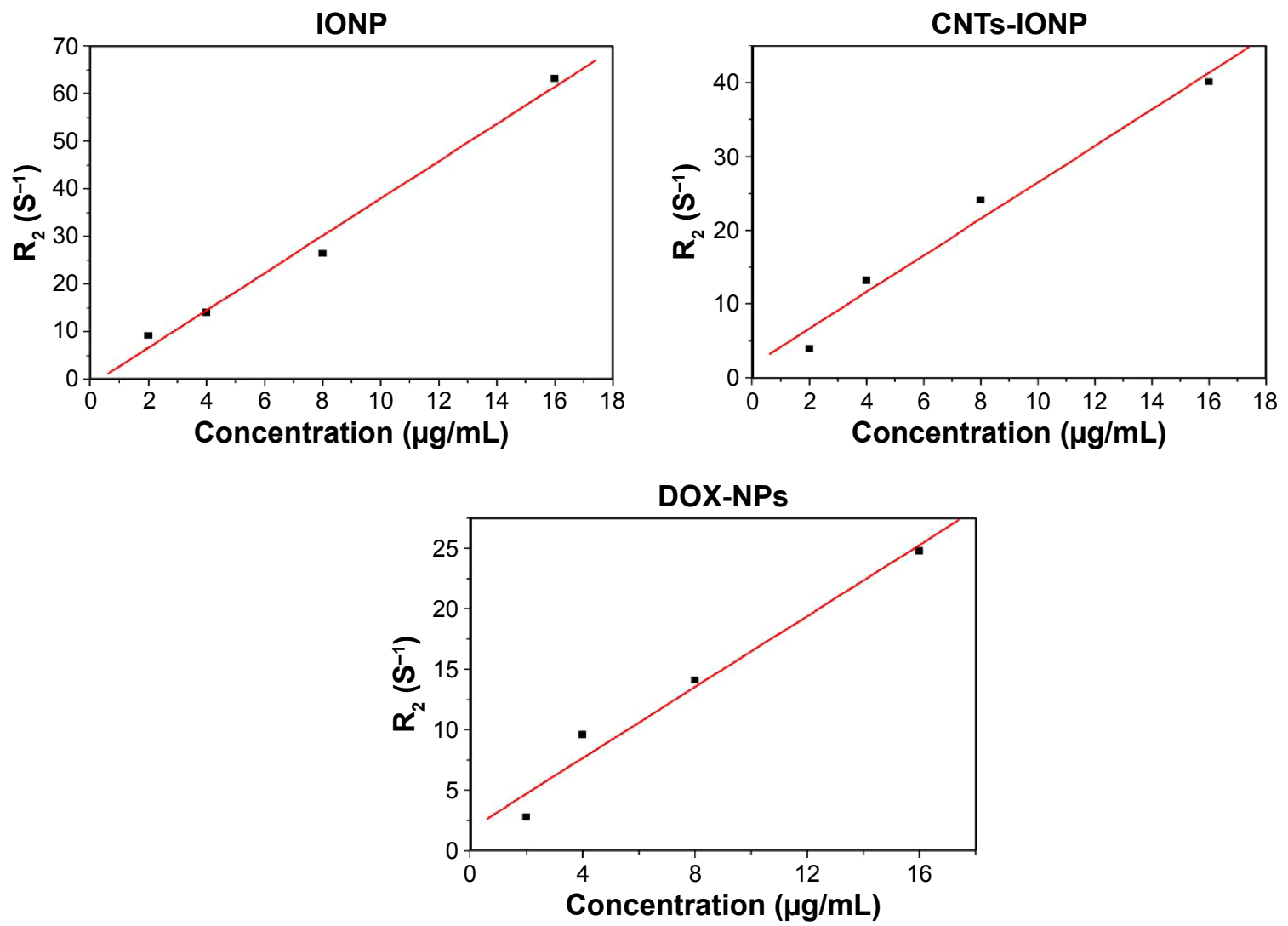

Figure $S I$ T $T_{2}$ relaxation rates $\left(R_{2}\right)$ of IONP, CNTs-IONP, and DOX-NPs solutions at different concentrations.

Abbreviations: CNTs, carbon nanotubes; DOX, doxorubicin; IONP, iron oxide nanoparticle; NPs, nanoparticles.

\section{Publish your work in this journal}

The International Journal of Nanomedicine is an international, peerreviewed journal focusing on the application of nanotechnology in diagnostics, therapeutics, and drug delivery systems throughout the biomedical field. This journal is indexed on PubMed Central, MedLine, CAS, SciSearch $\AA$, Current Contents $\AA /$ Clinical Medicine,

Journal Citation Reports/Science Edition, EMBase, Scopus and the Elsevier Bibliographic databases. The manuscript management system is completely online and includes a very quick and fair peer-review system, which is all easy to use. Visit http://www.dovepress.com/ testimonials.php to read real quotes from published authors. 